\title{
Synergistic enhancement of urban haze by nitrate uptake into transported hygroscopic particles in the Asian continental outflow
}

\author{
Jihoon Seo ${ }^{1,2}$, Yong Bin Lim $^{3}$, Daeok Youn ${ }^{4}$, Jin Young Kim ${ }^{1}$, and Hyoun Cher Jin ${ }^{1}$ \\ ${ }^{1}$ Environment, Health and Welfare Research Center, Korea Institute of Science and Technology, Seoul, 02792, South Korea \\ ${ }^{2}$ School of Earth and Environmental Sciences, Seoul National University, Seoul, 08826, South Korea \\ ${ }^{3}$ Department of Chemical Engineering and Material Science, Ewha Womans University, Seoul, 03760, South Korea \\ ${ }^{4}$ Department of Earth Science Education, Chungbuk National University, Cheongju, 28644, South Korea
}

Correspondence: Jin Young Kim (jykim@kist.re.kr)

Received: 18 December 2019 - Discussion started: 6 February 2020

Revised: 21 May 2020 - Accepted: 3 June 2020 - Published: 30 June 2020

\begin{abstract}
Haze pollution is affected by local air pollutants, regional transport of background particles and precursors, atmospheric chemistry related to secondary aerosol formation, and meteorological conditions conducive to physical, dynamical, and chemical processes. In the large, populated and industrialized areas like the Asian continental outflow region, the combination of regional transport and local stagnation often exacerbates urban haze pollution. However, the detailed chemical processes underlying the enhancement of urban haze induced by the combined effect of local emissions and transported remote pollutants are still unclear. Here, we demonstrate an important role of transported hygroscopic particles in increasing local inorganic aerosols, by studying the chemical composition of $\mathrm{PM}_{2.5}$ collected between October 2012 and June 2014 in Seoul, a South Korean megacity in the Asian continental outflow region, using the ISORROPIA II thermodynamic model. $\mathrm{PM}_{2.5}$ measured under the condition of regional transport from the upwind source areas in China was higher in mass concentration and richer in secondary inorganic aerosol (SIA) species $\left(\mathrm{SO}_{4}^{2-}, \mathrm{NO}_{3}^{-}\right.$, and $\mathrm{NH}_{4}^{+}$) and aerosol liquid water (ALW) compared to that measured under non-transport conditions. The secondary inorganic species and ALW were both increased, particularly in cases with high $\mathrm{PM}_{2.5}$ levels, and this indicates inorganic species as a major driver of hygroscopicity. We conclude that the urban haze pollution in a continental outflow region like Seoul, particularly during the cold season, can be exacerbated by ALW in the transported particles, which enhances the nitrate partitioning into the particle phase in $\mathrm{NO}_{x}$ - and
\end{abstract}

$\mathrm{NH}_{3}$-rich urban areas. This study reveals the synergistic effect of remote and local sources on urban haze pollution in the downwind region and provides insight into the nonlinearity of domestic and foreign contributions to receptor $\mathrm{PM}_{2.5}$ concentrations in numerical air quality models.

\section{Introduction}

Fine particulate matter (under $2.5 \mu \mathrm{m}$ in diameter; $\mathrm{PM}_{2.5}$ ) in urban areas consists of inorganic species $\left(\mathrm{SO}_{4}^{2-}, \mathrm{NO}_{3}^{-}\right.$, and $\mathrm{NH}_{4}^{+}$) and organic matter $(\mathrm{OM})$ produced by the gasto-particle conversion of anthropogenic and biogenic precursors (Seinfeld and Pandis, 2016). These particles pose a public health problem due to their adverse effects on the human respiratory and cardiovascular systems (Pope and Dockery, 2006). Consequently, many countries have tried to mitigate urban haze pollution by reducing local precursor emissions (van der A et al., 2017; Kim and Lee, 2018). However, since air pollution is also influenced by transported air pollutants, it is difficult to achieve improved air quality in megacities located in large, populated, and industrialized areas by controlling local emissions (Seo et al., 2018). Synoptic weather conditions cause stagnation and long-range transport that can lead to the accumulation of particles and gaseous precursors from local and remote sources. It can also change local meteorological factors to favorable conditions for secondary aerosol production, such as photo-oxidation and aqueous- 
phase processing (Sun et al., 2014; Zheng et al., 2015; Seo et al., 2017). Therefore, a better understanding of the combined effects of local emissions, regional transport, and meteorological conditions on urban haze pollution is required to establish appropriate mitigation strategies.

One key aerosol component that affects the formation and growth of haze particles is aerosol liquid water (ALW), which is ubiquitous and abundant in tropospheric fine particles (Nguyen et al., 2016). ALW not only increases the mass of secondary organic aerosols (SOAs) by facilitating the partitioning of gas-phase water-soluble OM into the condensed phase, followed by aqueous-phase reactions (Asa-Awuku et al., 2010; Carlton and Turpin, 2013; McNeill, 2015; Marais et al., 2016), but it also enhances the secondary inorganic aerosol (SIA) mass via nitrate formation through $\mathrm{HNO}_{3}$ uptake and $\mathrm{N}_{2} \mathrm{O}_{5}$ hydrolysis (Zhang et al., 2015; Wang et al., 2017) and via sulfate production through the aqueous oxidation of $\mathrm{SO}_{2}$ (Cheng et al., 2016; Wang et al., 2017). Studies of urban haze in the North China Plain reported a simultaneous elevation of the relative humidity (RH), ALW, and SIA, which indicates the hygroscopic properties of inorganic species and the role of ALW in mass transfer into the particles (Liu et al., 2017; Tie et al., 2017; Wu et al., 2018). Combined with the ambient temperature and particle $\mathrm{pH}, \mathrm{ALW}$ is critical for gas-particle partitioning of inorganic and water-soluble organic acid gases (Guo et al., 2018; Nah et al., 2018). Therefore, regional transport of wet particles to the precursor-rich urban environment will affect haze pollution downwind.

The South Korean capital city of Seoul and its metropoli$\tan$ area is one of the highly populated megacities in East Asia, with a population of 25 million people, 9 million vehicles, and nearly half of the national gross domestic product, and it has suffered from episodic haze events, particularly during the cold season (Seo et al., 2017, 2018). Although the Seoul metropolitan area is a large anthropogenic emission source of nitrogen oxides $\left(\mathrm{NO}_{x}\right)$, ammonia $\left(\mathrm{NH}_{3}\right)$, and volatile organic compounds (VOCs) (NIER, 2018), the effect of transported air pollutants from China cannot be ignored, because of its location downwind from the major emission source region in China like the North China Plain and Yangtze River Delta (Fig. S1 in the Supplement). In particular, severe multiday haze events in the Seoul metropolitan area mostly occur with a specific synoptic pattern, such as an eastward-moving high-pressure system, which induces regional transport of air pollutants from China and, subsequently, local stagnation (Seo et al., 2017, 2018). Therefore, the haze pollution in Seoul becomes severe primarily by the accumulation of local and transported air pollutants. However, a recent numerical modeling study on regional contribution to the particulate concentration in Seoul reported a discrepancy between responses to the reduction in domestic and foreign emissions (Kim et al., 2017), and this implies additional production and growth of local haze particles by non- linear interactions between local emissions and transported pollutants.

In this study, we explore the combined effects of local and remote sources, ALW and particle $\mathrm{pH}$, and meteorological factors on the formation and growth of urban haze particles, based on daily measurement of $\mathrm{PM}_{2.5}$ chemical compositions in Seoul, backward trajectory analysis, and the ISORROPIA II thermodynamic model (Fountoukis and Nenes, 2007). Different chemical compositions and characteristics of Seoul haze according to the regional transport from China and the local stagnation in the Seoul metropolitan area is investigated from the perspective of inorganic partitioning and water uptake processes. An effective strategy for $\mathrm{PM}_{2.5}$ reduction in Seoul is further discussed using ambient $\mathrm{NO}_{x}$ and $\mathrm{NH}_{3}$ levels and analytic calculation of the $\mathrm{HNO}_{3}-\mathrm{NO}_{3}^{-}$partitioning ratio as a function of $\mathrm{ALW}, \mathrm{pH}$, and temperature.

\section{Data and methods}

\subsection{Measurements and chemical analysis}

Daily $\mathrm{PM}_{2.5}$ sampling was conducted on 210 days between October 2012 and June 2014 at the Korea Institute of Science and Technology (KIST) site in northeastern Seoul $\left(37.603^{\circ} \mathrm{N}, 127.047^{\circ} \mathrm{E} ; 58 \mathrm{~m}\right.$ above sea level; Fig. S1). $\mathrm{PM}_{2.5}$ samples for determining inorganic and carbonaceous species were collected on $47 \mathrm{~mm}$ Teflon filters (Pall Corporation, Port Washington, NY, USA) with a Teflon-coated aluminum cyclone (URG Corporation, Chapel Hill, NC, USA) at a flow rate of $16.7 \mathrm{~L} \mathrm{~min}^{-1}$ and on $203 \times 254 \mathrm{~mm}$ quartz fiber filters (Whatman, Maidstone, UK) with a high-volume air sampler (flow rate of $1000 \mathrm{~L} \mathrm{~min}^{-1}$; Andersen Instruments, Atlanta, GA, USA), respectively.

The concentrations of inorganic ions $\left(\mathrm{SO}_{4}^{2-}, \mathrm{NO}_{3}^{-}, \mathrm{Cl}^{-}\right.$, $\mathrm{NH}_{4}^{+}, \mathrm{K}^{+}, \mathrm{Ca}^{2+}, \mathrm{Na}^{+}$, and $\mathrm{Mg}^{2+}$ ) were measured using a 2000i/SP ion chromatograph (Dionex, Sunnyvale, CA, USA) after sonicating the Teflon filter sample for $30 \mathrm{~min}$ in a mixture of $0.5 \mathrm{~mL}$ of ethanol and $14.5 \mathrm{~mL}$ of distilled deionized water. Using a piece of the quartz fiber filter sample $(10 \times 15 \mathrm{~mm})$, the concentrations of organic carbon (OC) and elemental carbon (EC) were measured using a thermal-optical carbon aerosol analyzer (Sunset Laboratory, Tigard, OR, USA) based on National Institute for Occupational Safety and Health (NIOSH) method 5040 (Birch and Cary, 1996). We also identified $17 n$-alkanes $\left(\mathrm{C}_{20}-\mathrm{C}_{36}\right)$, 15 polycyclic aromatic hydrocarbons (PAHs; $\mathrm{C}_{14}-\mathrm{C}_{24}$ ), 19 monocarboxylic acids $\left(\mathrm{C}_{6}-\mathrm{C}_{20}\right), 19$ dicarboxylic acids $\left(\mathrm{C}_{3}-\right.$ $\left.\mathrm{C}_{11}\right)$, and 10 sugars $\left(\mathrm{C}_{5}-\mathrm{C}_{6}\right.$ and $\left.\mathrm{C}_{12}\right)$ using the extract from one half of the quartz fiber filter sample and a 7890A gas chromatograph (Hewlett Packard, Palo Alto, CA, USA) coupled to a 5975C mass selective detector (Agilent, Santa Clara, CA, USA). The OM/OC ratios derived from the measured $\mathrm{OM}$ and $\mathrm{OC}$ concentrations were used to estimate the total OM concentration. The organic compounds identified 
in this study constitute $\sim 5 \%$ of the total OM. The analytical procedures used herein are described in detail elsewhere (Seo et al., 2017; Kim et al., 2018). In this study, out of 210 sampling days, 118 daily data that include not only inorganic species but also OM based on the identified organic compounds' information were selected and utilized (Fig. S2).

Note that the $\mathrm{PM}_{2.5}$ sampling on a Teflon filter for inorganic ions was conducted without either a denuder or backup filters, and thus there could be potential sampling artifacts in the results, particularly negative artifacts in semi-volatile ammonium nitrate (Ashbaugh and Eldred, 2004; Chow et al., 2005). Nie et al. (2010) reported that summertime nitrate loss on a Teflon filter from the un-denuded filter sampling without backup filters is $\sim 75 \%$ at lower nitrate concentrations $\left(<10 \mu \mathrm{g} \mathrm{m}^{-3}\right)$ but only $\sim 10 \%$ at higher nitrate concentrations $\left(>10 \mu \mathrm{g} \mathrm{m}^{-3}\right)$ due to the formation of particle cake. Considering small evaporative loss in the cold season and the high nitrate concentration in Seoul, we expected small to moderate sampling errors in this study. Sensitivity tests considering potential ammonium nitrate loss from the filter samples show that the assumption of $20 \%$ nitrate loss for the high concentrations with low-temperature groups and $50 \%$ nitrate loss for the low concentrations with moderate-temperature groups does not change our conclusion (Fig. S3).

The hourly concentrations of $\mathrm{SO}_{2}, \mathrm{NO}_{2}, \mathrm{CO}, \mathrm{O}_{3}$, and $\mathrm{PM}_{10}$ at 34 air quality monitoring sites in Seoul (Fig. S1) provided by the Korea Ministry of Environment were averaged over all sites for each day to obtain representative daily concentrations of each species for Seoul (Korea Environment Corporation, 2019). The hourly meteorological data of temperature, RH, wind speed, and solar irradiance at the Seoul weather station $\left(37.571^{\circ} \mathrm{N}, 126.966^{\circ} \mathrm{E}\right)$ managed by the Korea Meteorological Administration (KMA) were averaged for each day and used in our analysis (KMA, 2019). Boundary layer height (BLH) was derived from the European Centre for Medium-Range Weather Forecasts Reanalysis Interim (ERA-Interim) data (Dee et al., 2011; http:// apps.ecmwf.int/datasets/data/interim-full-daily/, last access: 23 October 2019) at a grid point in Seoul $\left(37.5^{\circ} \mathrm{N}, 127.0^{\circ} \mathrm{E}\right)$.

\subsection{Categorization of measurements}

To categorize the daily measurements according to (1) local atmospheric conditions (stagnation or ventilation) and (2) regional impact (transport of pollutants from upwind source area), we used the $72 \mathrm{~h}$ backward trajectories from $500 \mathrm{~m}$ above the sampling site, obtained with the Hybrid SingleParticle Lagrangian Integrated Trajectory (HYSPLIT) model (https://ready.arl.noaa.gov; Stein et al., 2015) for every hour of each measurement day. We defined a local source area (Seoul metropolitan area) and two major upwind source areas in China (North China Plain and Yangtze River Delta) based on the satellite tropospheric $\mathrm{NO}_{2}$ column density distribution (Fig. 1a) and calculated the average residence time of daily 24 trajectories in the Seoul metropolitan area $\left(t_{\mathrm{SMA}}\right)$ and the two source areas in China $\left(t_{\mathrm{CHN}}\right)$. The daily average residence time in each area shows different source characteristics such as the smaller sulfur-to-nitrogen emission ratio in Seoul $\left(\sim 0.06 ; 4.5 \mathrm{kt}\right.$ of $\mathrm{SO}_{x}$ and $71.1 \mathrm{kt}$ of $\mathrm{NO}_{x}$ in 2010; NIER, 2018) compared with that of the Jing-Jin-Ji region in the North China Plain $\left(\sim 0.71 ; 2010 \mathrm{kt}\right.$ of $\mathrm{SO}_{2}$ and $2830 \mathrm{kt}$ of $\mathrm{NO}_{x}$ in 2010; $\mathrm{Li}$ et al., 2017). For example, $t_{\mathrm{CHN}}$ is highly correlated not only with particulate $\mathrm{SO}_{4}^{2-}$ and $\mathrm{NO}_{3}^{-}$concentrations but also with their precursor $\left(\mathrm{SO}_{2}\right.$ and $\left.\mathrm{NO}_{2}\right)$ concentrations, while $t_{\mathrm{SMA}}$ has statistically significant correlation only with $\mathrm{NO}_{2}$ concentration (Fig. S4).

Since the medians of both $t_{\mathrm{SMA}}$ (for all measurement days) and $t_{\mathrm{CHN}}$ (for the measurement days with $t_{\mathrm{CHN}} \neq 0 \mathrm{~h}$ ) were $\sim 6 \mathrm{~h}$, we applied $6 \mathrm{~h}$ as a reference trajectory residence time to categorize daily measurement data into relatively stronger and weaker influences through the local stagnation in the Seoul metropolitan area (with $t_{\mathrm{SMA}}$ ) and the regional transport from China (with $t_{\mathrm{CHN}}$ ). The measurement days were classified into one of four groups and summarized in Table 1: (i) "local ventilation with no regional transport" (V-nT), in which the trajectories did not originate from the source areas in China and were also not stagnant in the Seoul metropolitan area ( $t_{\mathrm{SMA}}<6 \mathrm{~h}$ and $t_{\mathrm{CHN}}=0 \mathrm{~h} ; n=9 \mathrm{~d}$ ); (ii) "local stagnation with no regional transport" (S-nT), in which the trajectories did not originate from the source areas in China but were stagnant in the Seoul metropolitan area $\left(t_{\mathrm{SMA}} \geq 6 \mathrm{~h}\right.$ and $t_{\text {CHN }}=0 \mathrm{~h} ; n=15 \mathrm{~d}$ ); (iii) "local ventilation with regional transport" from the Chinese source area (V-T), in which the trajectories originated from the source areas in China but were not stagnant in the Seoul metropolitan area $\left(t_{\mathrm{SMA}}<6 \mathrm{~h}\right.$ and $t_{\mathrm{CHN}} \geq 6 \mathrm{~h} ; n=15 \mathrm{~d}$ ); and (iv) "local stagnation with regional transport" from the Chinese source area (S-T), in which the trajectories originated from the source areas in China and were also stagnant in the Seoul metropolitan area ( $t_{\mathrm{SMA}} \geq 6 \mathrm{~h}$ and $t_{\mathrm{CHN}} \geq 6 \mathrm{~h} ; n=21 \mathrm{~d}$ ). The trajectory density distribution in the North China Plain and Yangtze River Delta areas were characterized for each group, with few trajectories for the no regional-transport ( $\mathrm{V}-\mathrm{nT}$ and S-nT) groups but relatively dense trajectories for the regional-transport (V-T and S-T) groups (Fig. 1b-d).

Despite the various potential factors like emissions, atmospheric chemistry, and meteorology that can affect the gas and particulate air quality, the simple categorization according to the residence time of backward trajectories could reveal different characteristics in chemical species and meteorological factors associated with the local stagnation and the regional transport of air pollutants. For example, the average concentrations of primary gaseous pollutants $\left(\mathrm{SO}_{2}, \mathrm{NO}_{2}\right.$, and $\mathrm{CO}$ ) of the "local stagnation with regional transport" (S-T) group are significantly higher than those of the "local stagnation with no regional transport" (S-nT) group ( $p \leq 0.001)$, although average local meteorological factors between the two groups do not show significant differences (Table 2 and Figs. 2 and 3). On the other hand, the lower wind speed and shallower BLH were seen in the local stagnation (S-T 
(a) Tropospheric $\mathrm{NO}_{2}$

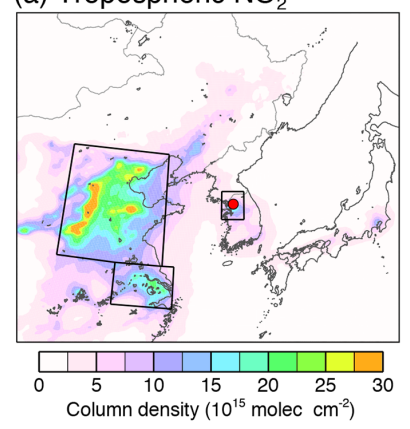

(b) V-nT (ventilation + non-transport)

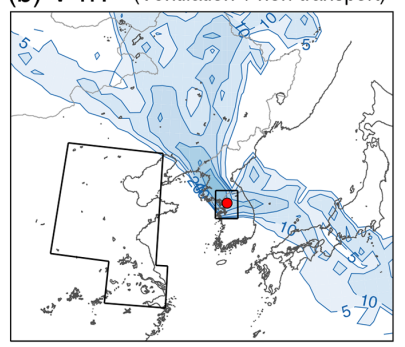

(c) S-nT (stagnation + non-transport)
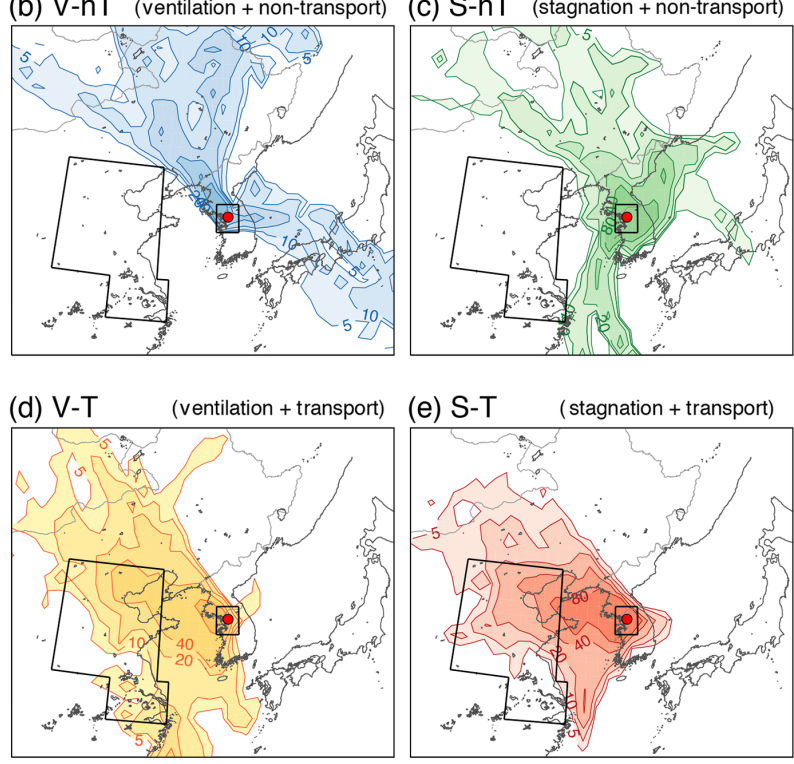

(e) S-T (stagnation + transport)

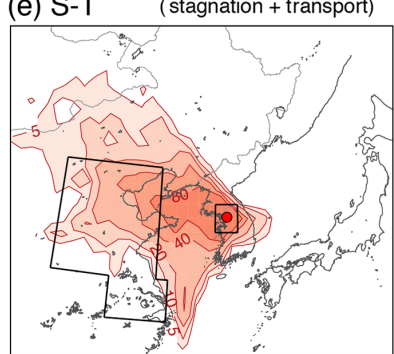

Figure 1. (a) Tropospheric $\mathrm{NO}_{2}$ column density obtained from the Ozone Monitoring Instrument (OMI) onboard the EOS-Aura satellite, averaged for 2012-2014, and the major anthropogenic emission areas defined in this study (North China Plain, NCP: 33-41 ${ }^{\circ}$ N, $112-$ $121^{\circ} \mathrm{E}$; Yangtze River Delta, YRD: $30-33^{\circ} \mathrm{N}, 117-122^{\circ} \mathrm{E}$; and Seoul metropolitan area, SMA; 36.5-38.5 $\left.{ }^{\circ} \mathrm{N}, 126-128^{\circ} \mathrm{E}\right) .(\mathbf{b}-\mathbf{e})$ Trajectory frequency (number of endpoints in each $1^{\circ} \times 1^{\circ}$ grid cell per number of trajectories, \%) derived from the HYSPLIT $72 \mathrm{~h}$ backward trajectories obtained $500 \mathrm{~m}$ above the Korea Institute of Science and Technology (KIST) site and average chemical compositions of particulate matter under $2.5 \mu \mathrm{m}$ in diameter $\left(\mathrm{PM}_{2.5}\right)$ for the (b) "local ventilation with no regional transport" (V-nT) group, (c) "local stagnation with no regional transport" (S-nT) group, (d) "local ventilation with regional transport" (V-T) group, and (e) "local stagnation with regional transport" (S-T) group. Seoul is marked with a solid red circle.

Table 1. List of four categorized groups of daily $\mathrm{PM}_{2.5}$ measurements in this study.

\begin{tabular}{|c|c|c|c|}
\hline Categories & Acronyms & $\begin{array}{l}\text { Trajectory residence time in the } \\
\text { Chinese source area }\left(t_{\mathrm{CHN}}\right)\end{array}$ & $\begin{array}{l}\text { Trajectory residence time in the } \\
\text { Seoul metropolitan area }\left(t_{\text {SMA }}\right)\end{array}$ \\
\hline "local ventilation with no regional transport" & V-nT & $t_{\mathrm{CHN}}=0 \mathrm{~h}$ & $t_{\mathrm{SMA}}<6 \mathrm{~h}$ \\
\hline "local stagnation with no regional transport" & S-nT & $t_{\mathrm{CHN}}=0 \mathrm{~h}$ & $t_{\mathrm{SMA}} \geq 6 \mathrm{~h}$ \\
\hline "local ventilation with regional transport" & $\mathrm{V}-\mathrm{T}$ & $t_{\mathrm{CHN}} \geq 6 \mathrm{~h}$ & $t_{\mathrm{SMA}}<6 \mathrm{~h}$ \\
\hline "local stagnation with regional transport" & $\mathrm{S}-\mathrm{T}$ & $t_{\mathrm{CHN}} \geq 6 \mathrm{~h}$ & $t_{\mathrm{SMA}} \geq 6 \mathrm{~h}$ \\
\hline
\end{tabular}

and S-nT) groups compared with the local-ventilation (V-T and V-nT) groups (Fig. 2), and the "local stagnation with regional transport" (S-T) group shows significantly higher levels of $\mathrm{SO}_{2}, \mathrm{NO}_{2}$, and $\mathrm{CO}$ in comparison with the "local ventilation with regional transport" (V-T) group, probably related to accumulation in the stagnant condition. Note that although the present study used a part of total daily data for which OM concentrations are available $(n=118)$, composite averages and differences in meteorological variables and air pollutant concentrations among the four categorized groups using the total daily data including the OMunavailable dates $(n=210)$ showed the same characteristics as shown in Figs. 2 and 3 (Fig. S5).

\subsection{Prediction of ALW content and $\mathrm{pH}$}

The ISORROPIA II thermodynamic model was run in forward mode to estimate ALW content associated with inorganic species, $\mathrm{pH}$, and the equilibrium gas-particle partitioning based on the daily $\mathrm{PM}_{2.5}$ ionic compositions, $\mathrm{RH}$, and temperature. ISORROPIA II uses total (gas- plus aerosolphase) measurements as inputs, under the metastable assumption (no solid precipitates). Recent validation studies demonstrate that the forward mode is influenced less by measurement errors and gives a more accurate $\mathrm{pH}$ than the reverse mode, which uses only the aerosol-phase composition as an input (Hennigan et al., 2015; Song et al., 2018).

The forward mode of ISORROPIA II requires the total $\mathrm{NH}_{3}$ (gas-phase $\mathrm{NH}_{3}$ plus particulate $\mathrm{NH}_{4}^{+}$), total $\mathrm{HNO}_{3}$ $\left(\mathrm{HNO}_{3}\right.$ plus particulate $\mathrm{NO}_{3}^{-}$), and total $\mathrm{Cl}$ (gas-phase $\mathrm{HCl}$ 
Table 2. The average and standard deviation of $\mathrm{PM}_{2.5}$ chemical composition, meteorological factors, related gas concentrations, thermodynamic model results and gas-particle partitioning ratios, and mass concentration ratios to wet $\mathrm{PM}_{2.5}\left(\mathrm{PM}_{2.5}\right.$ wet $)$ for the "local ventilation with no regional transport" (V-nT) group, the "local stagnation with no regional transport" (S-nT) group, the "local ventilation with regional transport" (V-T) group, and the "local stagnation with regional transport" (S-T) group and $p$ values derived from Welch's $t$ test for the composite differences between the S-T and S-nT groups and between the S-T and V-T groups.

\begin{tabular}{|c|c|c|c|c|c|c|c|}
\hline \multirow[t]{2}{*}{ Components } & \multirow[b]{2}{*}{ Units } & \multicolumn{4}{|c|}{$\begin{array}{l}\text { Composite average and } \\
\text { standard deviation }\end{array}$} & \multicolumn{2}{|c|}{$\begin{array}{l}p \text { values from } \\
\text { Welch's } t \text { test }\end{array}$} \\
\hline & & $\begin{array}{l}(\mathrm{V}-\mathrm{nT}) \\
(n=9)\end{array}$ & $\begin{array}{r}(\mathrm{S}-\mathrm{nT}) \\
(n=15)\end{array}$ & $\begin{array}{r}(\mathrm{V}-\mathrm{T}) \\
(n=15)\end{array}$ & $\begin{array}{r}(\mathrm{S}-\mathrm{T}) \\
(n=21)\end{array}$ & $\begin{array}{l}(\mathrm{S}-\mathrm{T}) \text { minus }(\mathrm{S}-\mathrm{nT}) \\
(\text { transport effect) }\end{array}$ & $\begin{array}{l}(\mathrm{S}-\mathrm{T}) \text { minus }(\mathrm{V}-\mathrm{T}) \\
\text { (stagnation effect) }\end{array}$ \\
\hline \multicolumn{8}{|c|}{ Meteorological factors } \\
\hline$T$ & $\left({ }^{\circ} \mathrm{C}\right)$ & $2.6 \pm 13.2$ & $15.2 \pm 11.5$ & $9.4 \pm 6.0$ & $9.3 \pm 8.5$ & $p=0.104$ & $p=0.967$ \\
\hline RH & $(\%)$ & $45.9 \pm 10.0$ & $53.5 \pm 10.2$ & $61.0 \pm 9.3$ & $51.8 \pm 11.7$ & $p=0.632$ & $p=0.013$ \\
\hline WS & $\left(\mathrm{m} \mathrm{s}^{-1}\right)$ & $3.5 \pm 0.7$ & $2.4 \pm 0.6$ & $3.2 \pm 0.9$ & $2.4 \pm 0.7$ & $p=0.824$ & $p=0.009$ \\
\hline SI & $\left(\mathrm{W} \mathrm{m}^{-2}\right)$ & $167 \pm 41$ & $172 \pm 53$ & $154 \pm 64$ & $137 \pm 67$ & $p=0.094$ & $p=0.445$ \\
\hline $\mathrm{BLH}^{\mathrm{a}}$ & (m) & $770 \pm 177$ & $550 \pm 210$ & $666 \pm 277$ & $457 \pm 165$ & $p=0.165$ & $p=0.016$ \\
\hline \multicolumn{8}{|c|}{ Gaseous species } \\
\hline $\mathrm{SO}_{2}$ & (ppb) & $4.6 \pm 0.6$ & $5.2 \pm 2.0$ & $6.6 \pm 2.2$ & $8.8 \pm 2.7$ & $p<0.001$ & $p=0.012$ \\
\hline $\mathrm{NO}_{2}$ & (ppb) & $27.4 \pm 4.1$ & $41.6 \pm 11.7$ & $41.2 \pm 9.5$ & $57.3 \pm 12.5$ & $p<0.001$ & $p<0.001$ \\
\hline $\mathrm{CO}$ & (ppm) & $0.42 \pm 0.05$ & $0.55 \pm 0.26$ & $0.66 \pm 0.28$ & $0.89 \pm 0.31$ & $p=0.001$ & $p=0.026$ \\
\hline $\mathrm{O}_{3}$ & $(\mathrm{ppb})$ & $24.6 \pm 7.0$ & $20.1 \pm 11.9$ & $23.1 \pm 10.5$ & $15.5 \pm 9.0$ & $p=0.219$ & $p=0.031$ \\
\hline $\mathrm{NH}_{3} \mathrm{~b}$ & $(\mathrm{ppb})$ & $4.9 \pm 4.1$ & $10.5 \pm 3.0$ & $10.2 \pm 3.4$ & $11.0 \pm 4.3$ & $p=0.668$ & $p=0.499$ \\
\hline \multicolumn{8}{|c|}{$\mathrm{PM}_{2.5}$ components } \\
\hline $\mathrm{PM}_{2.5}$ dry & $\left(\mu \mathrm{gm}^{-3}\right)$ & $19.9 \pm 4.8$ & $34.4 \pm 20.7$ & $53.3 \pm 33.7$ & $72.2 \pm 31.9$ & $p<0.001$ & $p=0.100$ \\
\hline $\mathrm{SO}_{4}^{2-}$ & $\left(\mu \mathrm{g} \mathrm{m}^{-3}\right)$ & $3.3 \pm 0.7$ & $5.8 \pm 4.1$ & $10.8 \pm 7.6$ & $16.7 \pm 11.2$ & $p<0.001$ & $p=0.069$ \\
\hline $\mathrm{NO}_{3}^{-}$ & $\left(\mu \mathrm{g} \mathrm{m}^{-3}\right)$ & $1.7 \pm 1.4$ & $5.4 \pm 7.3$ & $12.1 \pm 11.2$ & $17.6 \pm 12.1$ & $p<0.001$ & $p=0.166$ \\
\hline $\mathrm{NH}_{4}^{+}$ & $\left(\mu \mathrm{gm}^{-3}\right)$ & $1.6 \pm 0.5$ & $3.4 \pm 3.6$ & $6.9 \pm 5.7$ & $10.8 \pm 6.9$ & $p<0.001$ & $p=0.075$ \\
\hline $\mathrm{EC}^{4}$ & $\left(\mu \mathrm{g} \mathrm{m}^{-3}\right)$ & $1.4 \pm 0.6$ & $1.7 \pm 0.6$ & $1.6 \pm 0.6$ & $2.1 \pm 0.8$ & $p=0.128$ & $p=0.036$ \\
\hline $\mathrm{OM}$ & $\left(\mu \mathrm{gm}^{-3}\right)$ & $10.1 \pm 4.4$ & $15.3 \pm 10.1$ & $15.0 \pm 7.0$ & $22.9 \pm 8.6$ & $p=0.025$ & $p=0.005$ \\
\hline$W_{\mathrm{i}}$ & $\left(\mu \mathrm{gm}^{-3}\right)$ & $2.7 \pm 1.4$ & $7.4 \pm 7.5$ & $23.7 \pm 24.9$ & $22.2 \pm 18.6$ & $p=0.003$ & $p=0.853$ \\
\hline$W_{\mathrm{o}}$ & $\left(\mu \mathrm{g} \mathrm{m}^{-3}\right)$ & $0.9 \pm 0.4$ & $2.2 \pm 1.7$ & $3.1 \pm 2.7$ & $3.3 \pm 2.3$ & $p=0.087$ & $p=0.833$ \\
\hline \multicolumn{8}{|c|}{ Carbonaceous analysis } \\
\hline $\mathrm{O} / \mathrm{C}$ & (atomic ratio) & $0.55 \pm 0.11$ & $0.55 \pm 0.07$ & $0.54 \pm 0.04$ & $0.55 \pm 0.07$ & $p=0.883$ & $p=0.622$ \\
\hline $\mathrm{OM} / \mathrm{OC}$ & (mass ratio) & $1.87 \pm 0.15$ & $1.87 \pm 0.10$ & $1.86 \pm 0.05$ & $1.87 \pm 0.08$ & $p=0.927$ & $p=0.632$ \\
\hline $\mathrm{OC} / \mathrm{EC}$ & (mass ratio) & $4.2 \pm 1.7$ & $4.8 \pm 2.4$ & $5.7 \pm 2.5$ & $6.2 \pm 2.1$ & $p=0.071$ & $p=0.510$ \\
\hline \multicolumn{8}{|c|}{ ISORROPIA II analysis } \\
\hline Ionic strength & $(M)$ & $54.3 \pm 16.2$ & $42.2 \pm 17.6$ & $30.6 \pm 10.3$ & $47.1 \pm 22.7$ & $p=0.470$ & $p=0.006$ \\
\hline $\mathrm{pH}$ & & $3.1 \pm 0.6$ & $3.2 \pm 0.7$ & $3.5 \pm 0.5$ & $3.5 \pm 0.7$ & $p=0.186$ & $p=0.808$ \\
\hline \multicolumn{8}{|c|}{ Oxidation/partitioning } \\
\hline SOR & (molar ratio) & $0.13 \pm 0.04$ & $0.19 \pm 0.07$ & $0.25 \pm 0.09$ & $0.28 \pm 0.12$ & $p=0.006$ & $p=0.439$ \\
\hline$\varepsilon\left(\mathrm{NO}_{3}^{-}\right)$ & (molar ratio) & $0.83 \pm 0.28$ & $0.67 \pm 0.31$ & $0.93 \pm 0.09$ & $0.90 \pm 0.19$ & $p=0.017$ & $p=0.481$ \\
\hline$\varepsilon\left(\mathrm{NH}_{4}^{+}\right)$ & (molar ratio) & $0.40 \pm 0.27$ & $0.25 \pm 0.14$ & $0.43 \pm 0.18$ & $0.52 \pm 0.18$ & $p<0.001$ & $p=0.150$ \\
\hline
\end{tabular}

${ }^{a}$ Reanalysis data from the ERA-Interim at $37.5^{\circ} \mathrm{N}, 127.0^{\circ}$ E. ${ }^{\mathrm{b}}$ Statistically reconstructed data based on Phan et al. (2013). T: temperature; RH: relative humidity; WS: wind speed; SI: solar irradiance; BLH: boundary layer height; EC: elemental carbon; OM: organic matter; $W_{\mathrm{i}}$ : aerosol liquid water (ALW) content associated with inorganic species; $W_{\mathrm{o}}$ : ALW content associated with $\mathrm{OM}$; OC: organic carbon; SOR: sulfur oxidation ratio; $\varepsilon\left(\mathrm{NO}_{3}^{-}\right)$: nitrate partitioning ratio; $\varepsilon\left(\mathrm{NH}_{4}^{+}\right)$: ammonium partitioning ratio.

plus particulate $\mathrm{Cl}^{-}$) concentrations, as well as the particulate $\mathrm{SO}_{4}^{2-}, \mathrm{K}^{+}, \mathrm{Ca}^{2+}, \mathrm{Na}^{+}$, and $\mathrm{Mg}^{2+}$ concentrations. However, the ambient $\mathrm{NH}_{3}, \mathrm{HNO}_{3}$, and $\mathrm{HCl}$ data were not available for this study. To overcome this problem with the input data, we used statistically reconstructed $\mathrm{NH}_{3}$ data and then estimated $\mathrm{HNO}_{3}$ using a thermodynamic model.

Firstly, the daily $\mathrm{NH}_{3}$ concentrations in Seoul from January 2012 to December 2014 were reconstructed using the statistical characteristics of a year-long record of $\mathrm{NH}_{3}$ at 
(a) $\mathrm{T}$

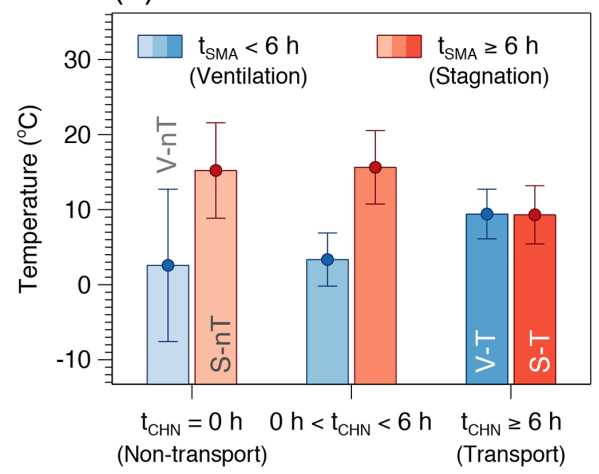

(c) WS

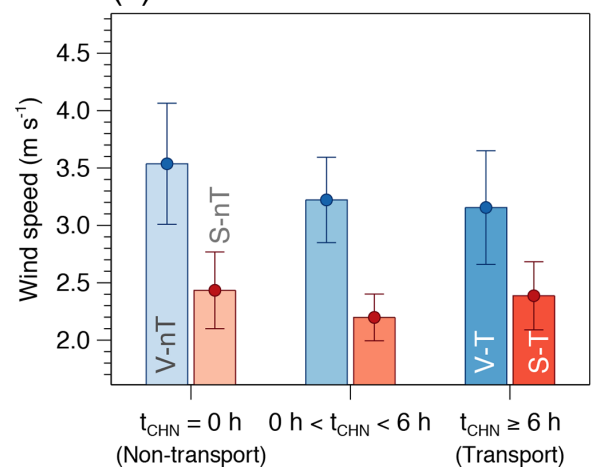

(b) $\mathrm{RH}$

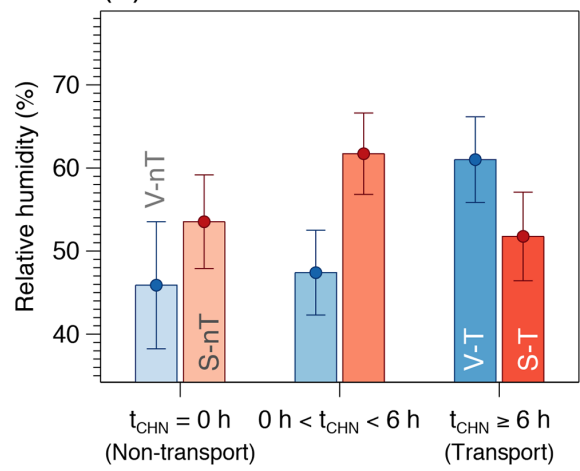

(d) BLH

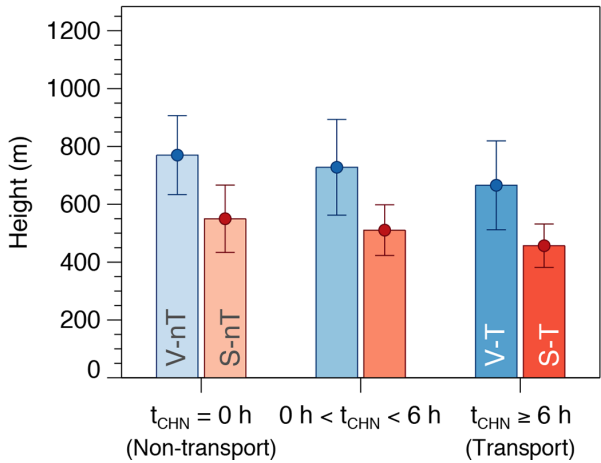

Figure 2. Averages and confidence intervals at $95 \%$ of (a) temperature $(T)$, (b) relative humidity (RH), (c) wind speed (WS), and (d) boundary layer height $(\mathrm{BLH})$ for the six case groups categorized by the ranges of the average daily residence time of backward trajectories in the Seoul metropolitan area $\left(t_{\mathrm{SMA}}\right)$ and in the North China Plain and Yangtze River Delta $\left(t_{\mathrm{CHN}}\right)$.

the Gwangjin site $\left(37.545^{\circ} \mathrm{N}, 127.096^{\circ} \mathrm{E}\right)$ in Seoul for the preceding year (346d between September 2010 and August 2011; Phan et al., 2013). There were small interannual changes in the estimated $\mathrm{NH}_{3}$ emission in Seoul (Fig. S6; NIER, 2018), and the two sites both share similar environments located downwind from the downtown core under the prevailing westerlies and surrounded by residential and small urban green areas (Fig. S1). Therefore, we assumed that the statistical characteristics of both sites and periods would be similar despite the temporal gap $(\sim 1-$ 3 years) and spatial distance $(\sim 7.8 \mathrm{~km})$ between this study and Phan et al. (2013). We built a multiple linear regression model of $\mathrm{NH}_{3}$ that retains statistical characteristics of the measured $\mathrm{NH}_{3}$ such as the annual average and standard deviation of $10.9 \pm 4.25 \mathrm{ppb}$ and the significant linear correlations $(p<0.05)$ with temperature, $\mathrm{RH}$, wind speed, and $\mathrm{SO}_{2}, \mathrm{NO}_{2}$, and $\mathrm{CO}$ concentrations (Text $\mathrm{S} 1$ and Table $\mathrm{S} 1$ in the Supplement). The reconstructed $\mathrm{NH}_{3}$ concentration is seasonally high during the warm season as reported by Phan et al. (2013) and shows high peaks on the polluted days with stagnant condition in the cold season (Fig. S7).

In the next step, the ISORROPIA II calculation was performed, using the reconstructed $\mathrm{NH}_{3}$ and measured $\mathrm{NH}_{4}^{+}$ as the total equivalent $\mathrm{NH}_{3}$, and the measured $\mathrm{NO}_{3}^{-}$alone as the total $\mathrm{HNO}_{3}$, to estimate the $\mathrm{HNO}_{3}-\mathrm{NO}_{3}^{-}$partitioning ratio. Then, using both the measured $\mathrm{NO}_{3}^{-}$and the ratio between the $\mathrm{HNO}_{3}$ and $\mathrm{NO}_{3}^{-}$predicted from the initial result, we estimated the ambient $\mathrm{HNO}_{3}$. Note that we regarded the $\mathrm{HNO}_{3} / \mathrm{NO}_{3}^{-}$ratio as approximately independent of the total $\mathrm{HNO}_{3}$. Although the nitrate partitioning depends on temperature, ALW content, and $\mathrm{pH}$ in general, the $\mathrm{HNO}_{3} / \mathrm{NO}_{3}^{-}$ratio is affected only by $\mathrm{pH}$ because both temperature and ALW are independent variables in this step. In the existence of excess $\mathrm{NH}_{3}$ as we assumed for Seoul ( $\sim 10 \mathrm{ppb}$ at the first step), changes in $\mathrm{pH}$ by total $\mathrm{HNO}_{3}$ are limited owing to the buffering effect of $\mathrm{NH}_{3}-\mathrm{NH}_{4}^{+}$partitioning (Weber et al., 2016; Guo et al., 2018; Lim et al., 2020). The $\mathrm{pH}$, nitrate partitioning ratio $\left[\varepsilon\left(\mathrm{NO}_{3}^{-}\right)=\mathrm{NO}_{3}^{-} /\left(\mathrm{HNO}_{3}+\mathrm{NO}_{3}^{-}\right)\right]$, and the ammonium partitioning ratios $\left[\varepsilon\left(\mathrm{NH}_{4}^{+}\right)=\mathrm{NH}_{4}^{+} /\left(\mathrm{NH}_{3}+\mathrm{NH}_{4}^{+}\right)\right]$ from the ISORROPIA simulations with and without gasphase $\mathrm{HNO}_{3}$ information show negligible differences to each other (Fig. 4d-f), unlike the significant role of additional $\mathrm{NH}_{3}$ information in increasing $\mathrm{pH}$ and $\varepsilon\left(\mathrm{NO}_{3}^{-}\right)$and decreasing $\varepsilon\left(\mathrm{NH}_{4}^{+}\right)$(Fig. $\left.4 \mathrm{a}-\mathrm{c}\right)$.

Finally, we repeated the ISORROPIA simulation with both total $\mathrm{NH}_{3}$ and total $\mathrm{HNO}_{3}$ estimated from the previous steps. Here we did not consider $\mathrm{HCl}-\mathrm{Cl}^{-}$partitioning because the 
(a) $\mathrm{SO}_{2}$

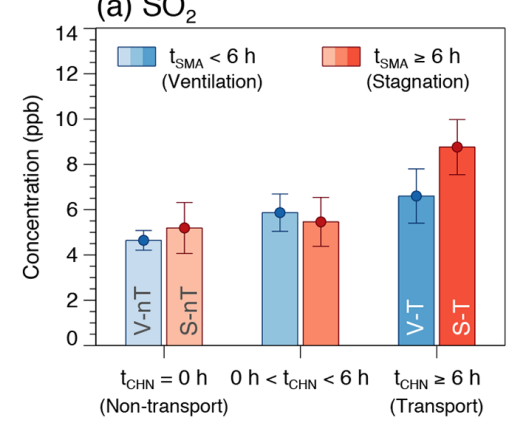

(d) $\mathrm{CO}$

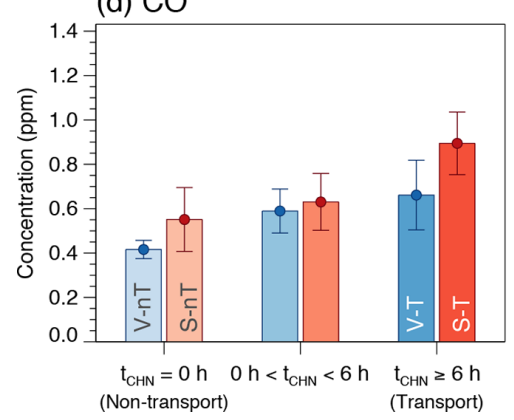

(b) $\mathrm{NO}_{2}$

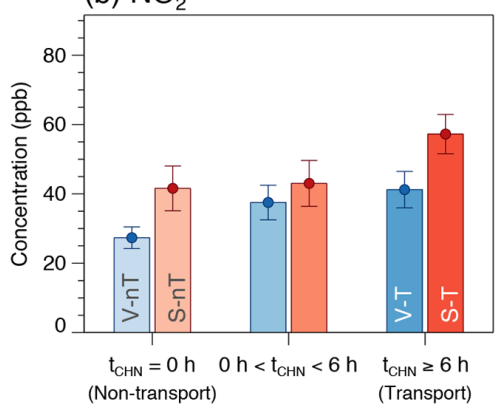

(e) $\mathrm{PM}_{10}$

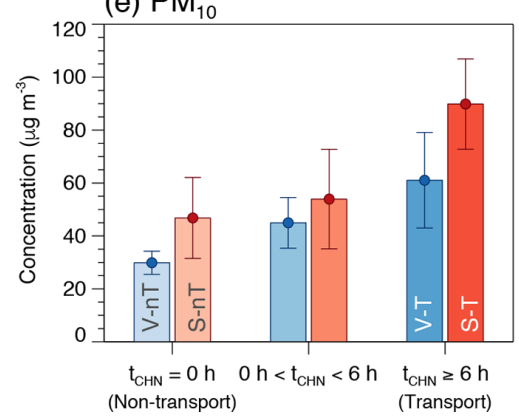

(c) $\mathrm{O}_{3}$
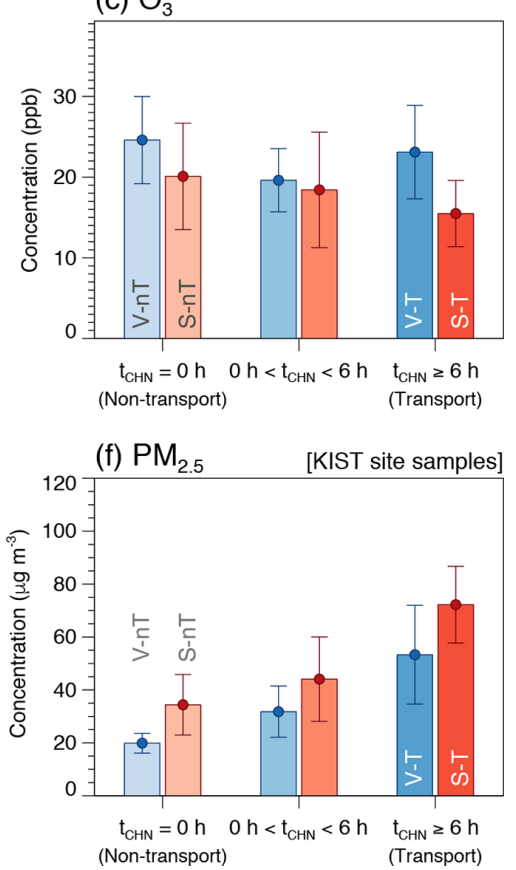

Figure 3. Averages and confidence intervals at $95 \%$ of daily average concentrations of (a) $\mathrm{SO}_{2}$, (b) $\mathrm{NO}_{2}$, (c) $\mathrm{O}_{3}$, (d) $\mathrm{CO}$, and (e) $\mathrm{PM}_{10}$, together with (f) $\mathrm{PM}_{2.5}$ measured at the KIST site in this study $\left(\mathrm{dry} \mathrm{PM}_{2.5}\right)$ for the six case groups categorized by ranges of the average daily residence time of backward trajectories in the Seoul metropolitan area $\left(t_{\mathrm{SMA}}\right)$ and in the North China Plain and Yangtze River Delta $\left(t_{\mathrm{CHN}}\right)$.

$\mathrm{Cl}^{-}$fraction in dry $\mathrm{PM}_{2.5}(\sim 1 \%$ on average $)$ is significantly smaller than the $\mathrm{NO}_{3}^{-}$and $\mathrm{NH}_{4}^{+}$fractions $(\sim 18 \%$ and $\sim 12 \%$ on average, respectively).

Although there are uncertainties in the reconstructed $\mathrm{NH}_{3}$ and $\mathrm{HNO}_{3}$ due to lack of direct measurements, their impact on the estimation of inorganic ALW and particle $\mathrm{pH}$ is small enough to utilize them for the thermodynamic analysis in this study. The good agreement between the predicted and statistically reconstructed $\mathrm{NH}_{3}$ concentrations $\left(R^{2} \sim 0.95\right)$, as well as between the predicted and measured $\mathrm{SO}_{4}^{2-}, \mathrm{NO}_{3}^{-}$, and $\mathrm{NH}_{4}^{+}$concentrations ( $R^{2}>0.95$; Fig. S8), ensures small errors in water contents of individual inorganic species. Since water uptake by inorganic aerosol in ISORROPIA II is based on the Zdanovskii-Stokes-Robinson (ZSR) mixing rule (Stokes and Robinson, 1966), which approximates the water content of a mixture as a sum of water contents of individual salts at the same RH (Fountoukis and Nenes, 2007), the expected error in $W_{\mathrm{i}}$ induced by potential errors in $\mathrm{NH}_{3}$ and $\mathrm{HNO}_{3}$ would also be small. Regarding $\mathrm{pH}$, the buffering effect of semi-volatile $\mathrm{NH}_{3}$ partitioning reduces the sensitivity of $\mathrm{pH}$ to excess $\mathrm{NH}_{3}$ in the $\mathrm{NH}_{3}$-rich conditions like Seoul (Weber et al., 2016; Guo et al., 2018; Lim et al., 2020). We conducted ISORROPIA simulations with various $\mathrm{NH}_{3} \mathrm{lev}$ els $(0-50 \mathrm{ppb})$ applied to all the measurement days as fixed values to further explore the sensitivity of $\mathrm{pH}, \varepsilon\left(\mathrm{NO}_{3}^{-}\right)$, and $\varepsilon\left(\mathrm{NH}_{4}^{+}\right)$to $\mathrm{NH}_{3}$. Good correlations between results from the daily varied- $\mathrm{NH}_{3}$ simulation and the fixed- $\mathrm{NH}_{3}$ simulations show that potential errors induced by the estimation of daily
$\mathrm{NH}_{3}$ levels will be small if $\mathrm{NH}_{3}$ concentrations are nonzero (Fig. 5a, c, and e). The slopes of $\mathrm{pH}, \varepsilon\left(\mathrm{NO}_{3}^{-}\right)$, and $\varepsilon\left(\mathrm{NH}_{4}^{+}\right)$ curves to the increase in fixed- $\mathrm{NH}_{3}$ level become gradually flat at over $5 \mathrm{ppb}$ (Fig. 5b, d, and f), and this indicates that the potential errors in reconstructed $\mathrm{NH}_{3}$ will not significantly change the results in this study.

Since ALW content associated with OM $\left(W_{\mathrm{o}}\right)$ is not considered in ISORROPIA II, we estimated it according to $\kappa$ Köhler theory and the ZSR mixing rule (Nguyen et al., 2015, and references therein) using the following equation:

$W_{\mathrm{o}}=V_{\mathrm{o}} \kappa_{\mathrm{org}} \frac{a_{\mathrm{w}}}{1-a_{\mathrm{w}}}$,

where $V_{\mathrm{o}}$ is the volume of $\mathrm{OM}\left(\mu \mathrm{m}^{3} \mathrm{~cm}^{-3}\right)$, which is obtained from OM concentration $\left(\mu \mathrm{g} \mathrm{m}^{-3}\right)$ divided by a typical organic density of $1.4 \mathrm{~g} \mathrm{~cm}^{-3}$ (Turpin and Lim, 2001), $\kappa_{\text {org }}$ is the hygroscopicity parameter (dimensionless) calculated from the parameterized relationship of $\kappa_{\mathrm{org}}=(0.29 \pm 0.05)$. $(\mathrm{O} / \mathrm{C})$ for the range of $\mathrm{O} / \mathrm{C}$ from 0.3 to 0.6 (Chang et al., 2010), and $a_{\mathrm{w}}$ is water activity (dimensionless) that is assumed to be equivalent to RH (Nguyen et al., 2016). 
Simulation 2 (with estimated $\mathrm{NH}_{3}$ gas) vs. Simulation 1 (without $\mathrm{NH}_{3}$ and $\mathrm{HNO}_{3}$ information)
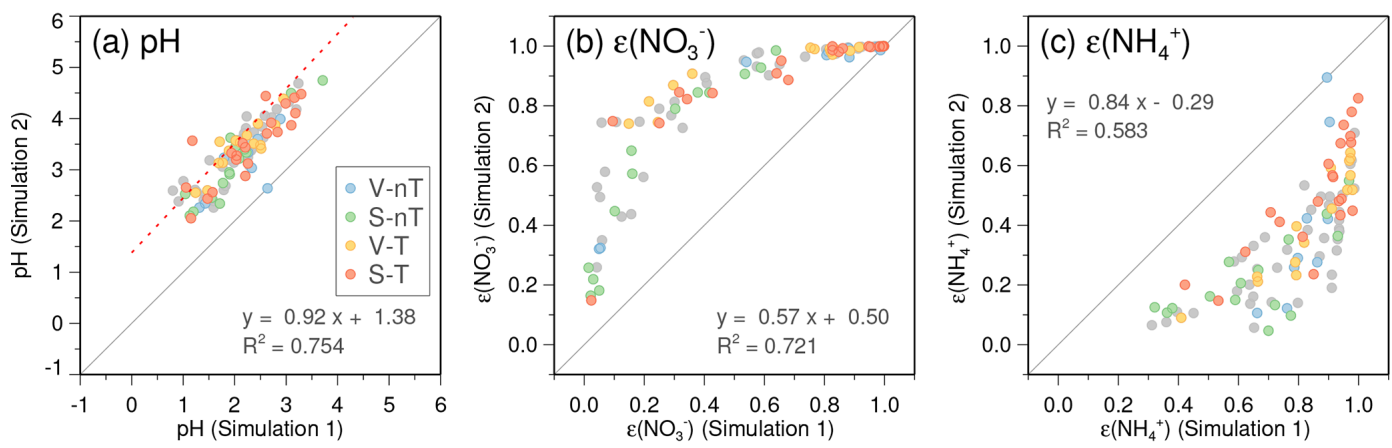

Simulation 3 (with both estimated $\mathrm{NH}_{3}$ and $\mathrm{HNO}_{3}$ gases) vs. Simulation 2
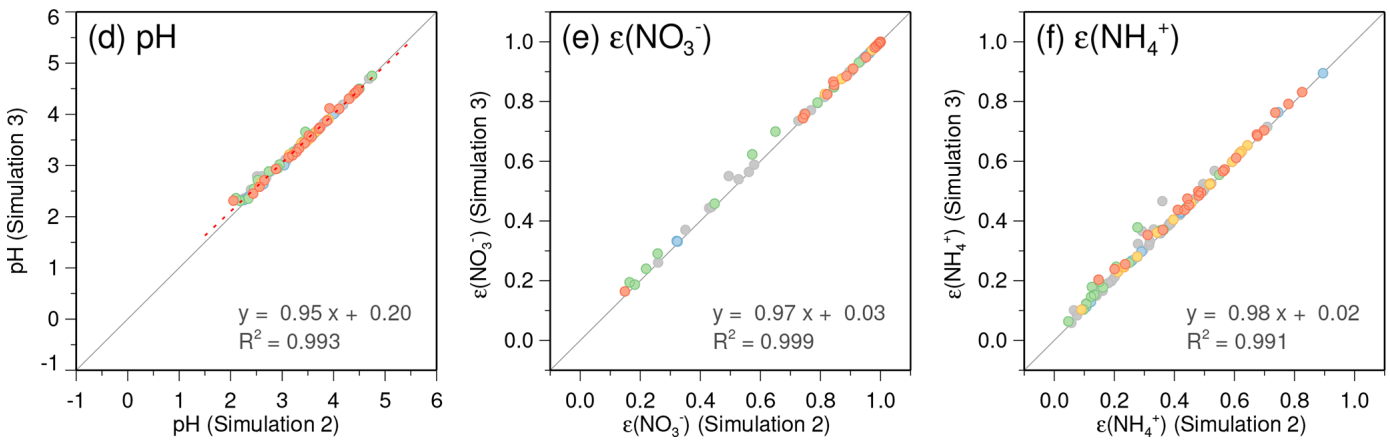

Figure 4. Comparisons of the predicted $\mathrm{pH}$, nitrate partitioning ratio $\left[\varepsilon\left(\mathrm{NO}_{3}^{-}\right)=\mathrm{NO}_{3}^{-} /\left(\mathrm{HNO}_{3}+\mathrm{NO}_{3}^{-}\right)\right]$, and ammonium partitioning ratio $\left[\varepsilon\left(\mathrm{NH}_{4}^{+}\right)=\mathrm{NH}_{4}^{+} /\left(\mathrm{NH}_{3}+\mathrm{NH}_{4}^{+}\right)\right]$between (a-c) the simulation without gas-phase $\mathrm{NH}_{3}$ and $\mathrm{HNO}_{3}$ information (using $\mathrm{NH}_{4}^{+}$and $\mathrm{NO}_{3}^{-}$as the total $\mathrm{NH}_{3}$ and total $\mathrm{HNO}_{3}$; Simulation 1) and the simulation with reconstructed $\mathrm{NH}_{3}$ (using $\mathrm{NH}_{3}+\mathrm{NH}_{4}^{+}$as the total $\mathrm{NH}_{3}$ but only $\mathrm{NO}_{3}^{-}$as the total $\mathrm{HNO}_{3}$; Simulation 2) and between (d-f) Simulation 2 and the simulation with both estimated gas-phase $\mathrm{NH}_{3}$ and $\mathrm{HNO}_{3}$ information (this study; Simulation 3). Filled circles in light blue, light green, light yellow, and light red colors represent daily data and belong to the "local ventilation with no regional transport" (V-nT) group, "local stagnation with no regional transport" (S-nT) group, "local ventilation with regional transport" (V-T) group, and "local stagnation with regional transport" (S-T) group, respectively. Gray solid lines indicate a 1-to-1 relationship.

\section{Results and discussion}

\subsection{Effects of regional transport and local stagnation on $\mathbf{P M}_{2.5}$ composition}

Average concentrations of $\mathrm{PM}_{2.5}$ and chemical components were highest in the "local stagnation with regional transport" (S-T) group (e.g., $\mathrm{PM}_{2.5}$ dry of $72.2 \mu \mathrm{g} \mathrm{m}^{-3}$ ) and lowest in the "local ventilation with no regional transport" (V-nT) group (e.g., $\mathrm{PM}_{2.5}$ dry of $19.9 \mu \mathrm{g} \mathrm{m}^{-3}$ ), and the average concentrations for the "local ventilation with regional transport" (V-T) group and the "local stagnation with no regional transport" (S-nT) groups (e.g., $\mathrm{PM}_{2.5}$ dry of 53.3 and $34.4 \mathrm{\mu g} \mathrm{m}^{-3}$, respectively) were located between those of the S-T and VnT groups (Table 2 and Fig. 3f). The composite difference between the regional-transport ( $\mathrm{V}-\mathrm{T}$ and $\mathrm{S}-\mathrm{T})$ groups and no regional-transport (V-nT and S-nT) groups reveals the regional effect of transported haze particles and precursors from the North China Plain and Yangtze River Delta, while that between the local-stagnation (S-T and S-nT) groups and local-ventilation (V-T and V-nT) groups shows the effect of accumulation or diffusion of both local and transported pollutants in the Seoul metropolitan area. Thus, the significant difference in each $\mathrm{PM}_{2.5}$ component between the S-T and VnT groups (Fig. 6) indicates both contributions of local stagnant conditions over the Seoul metropolitan area and regional transport from the Chinese source area to the exacerbation of haze pollution in Seoul.

The average concentrations of gaseous precursors like $\mathrm{SO}_{2}$ and $\mathrm{NO}_{2}$ for the S-T group were about 2 times higher than those for the V-nT group (Fig. 3), while $\mathrm{SO}_{4}^{2-}, \mathrm{NO}_{3}^{-}, \mathrm{NH}_{4}^{+}$, and inorganic ALW increased by 5-10 times (Fig. 6). In contrast, average OM concentration for the S-T group was 2 times higher than that for the V-nT group, similarly to $\mathrm{CO}$, and organic ALW of the S-T group showed a relatively smaller increase ( $\sim 4$ times of the V-nT group) than inorganic ALW ( $\sim 8$ times of the V-nT group). Therefore, the $\mathrm{PM}_{2.5}$ increase in Seoul seems to be induced not only by the physical and dynamical processes like transport or accumulation of air pollutants but also by the chemical process like 

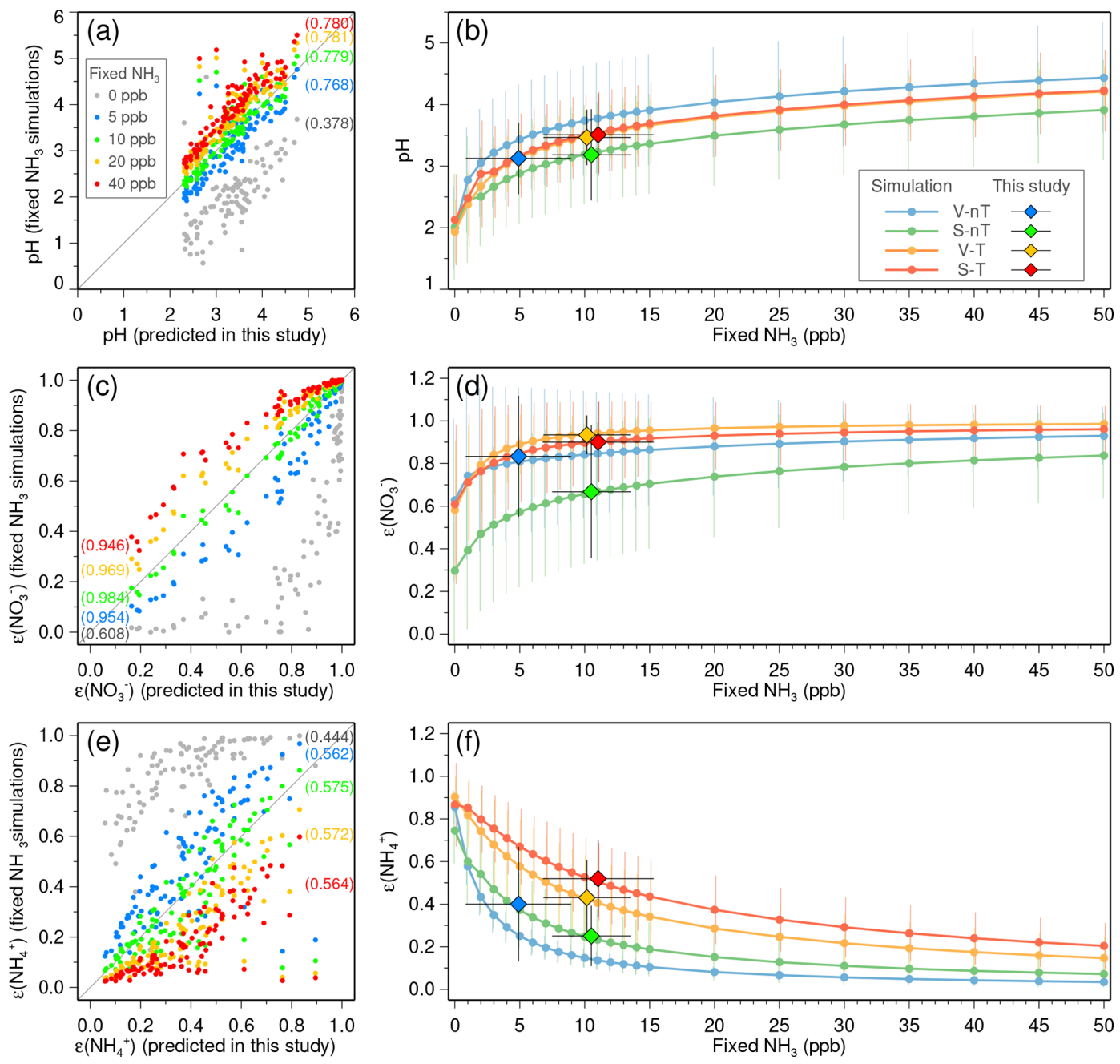

Figure 5. Sensitivity of $(\mathbf{a}-\mathbf{b})$ predicted $\mathrm{pH},(\mathbf{c}-\mathbf{d})$ nitrate partitioning ratio $\left[\varepsilon\left(\mathrm{NO}_{3}^{-}\right)=\mathrm{NO}_{3}^{-} /\left(\mathrm{HNO}_{3}+\mathrm{NO}_{3}^{-}\right)\right]$, and $(\mathbf{e}-\mathbf{f})$ ammonium partitioning ratio $\left[\varepsilon\left(\mathrm{NH}_{4}^{+}\right)=\mathrm{NH}_{4}^{+} /\left(\mathrm{NH}_{3}+\mathrm{NH}_{4}^{+}\right)\right]$to gas-phase ammonia $\left(\mathrm{NH}_{3}\right)$ concentrations. (a, $\mathbf{c}$, e) Comparisons between the simulation in this study (using the daily reconstructed $\mathrm{NH}_{3}$ concentrations) and the simulations with the various fixed- $\mathrm{NH}_{3}$ levels (colored dots in gray, blue, green, yellow, and red for $0,5,10,20$, and $40 \mathrm{ppb}$, respectively). Values in round brackets are the $R$-squared values of the linear regressions. Gray solid lines indicate a 1-to-1 relationship. (b, d, f) Average (solid circles) and standard deviation (vertical bars) of $\mathrm{pH} \varepsilon\left(\mathrm{NO}_{3}^{-}\right)$, and $\varepsilon\left(\mathrm{NH}_{4}^{+}\right)$for the "local ventilation with no regional transport" (V-nT) group (light blue), "local stagnation with no regional transport" (SnT) group (light green), "local ventilation with regional transport" (V-T) group (light yellow), and "local stagnation with regional transport" (S-T) group (light red) with respect to the various fixed- $\mathrm{NH}_{3}$ levels from 0 to $50 \mathrm{ppb}$. Averages and standard deviations of the reconstructed $\mathrm{NH}_{3}$ concentrations and obtained $\mathrm{pH}, \varepsilon\left(\mathrm{NO}_{3}^{-}\right)$, and $\varepsilon\left(\mathrm{NH}_{4}^{+}\right)$for the V-nT, S-nT, V-T, and S-T groups are represented as blue, green, yellow, and red diamonds with horizontal and vertical bars.

secondary aerosol formation, particularly related to the increase in inorganic species and ALW.

A statistically significant difference $(p<0.05)$ between the S-T and S-nT groups (effect of regional transport in the local stagnant condition) was observed in SIA species $\left(\mathrm{SO}_{4}^{2-}, \mathrm{NO}_{3}^{-}\right.$, and $\mathrm{NH}_{4}^{+}$), OM, and $\mathrm{ALW}$ (both $W_{\mathrm{i}}$ and $W_{\mathrm{o}}$ ), and that between the S-T and V-T groups (effect of local stagnation in the regional-transport condition) was seen for EC and OM (Table 2). Thus, although both regional transport and local stagnation can induce high concentrations of $\mathrm{PM}_{2.5}$ and its chemical components of the S-T group, the effect of regional transport is more significant for the increase in inorganic species and water content, while the effect of local stagnation is more significant for the increase in carbonaceous species. The sulfur oxidation ratio [SOR $\left.=\mathrm{SO}_{4}^{2-} /\left(\mathrm{SO}_{2}+\mathrm{SO}_{4}^{2-}\right)\right]$, nitrate partitioning ratio $\left[\varepsilon\left(\mathrm{NO}_{3}^{-}\right)\right]$, and ammonium partitioning ratio $\left[\varepsilon\left(\mathrm{NH}_{4}^{+}\right)\right]$of the $\mathrm{S}$ - $\mathrm{T}$ group, which were significantly higher than that of the S-nT group $(p<0.05)$ but did not clearly differ from that of the V-T group, indicate that the increase in SIA through the regionaltransport effect is closely associated with the enhanced oxi- 

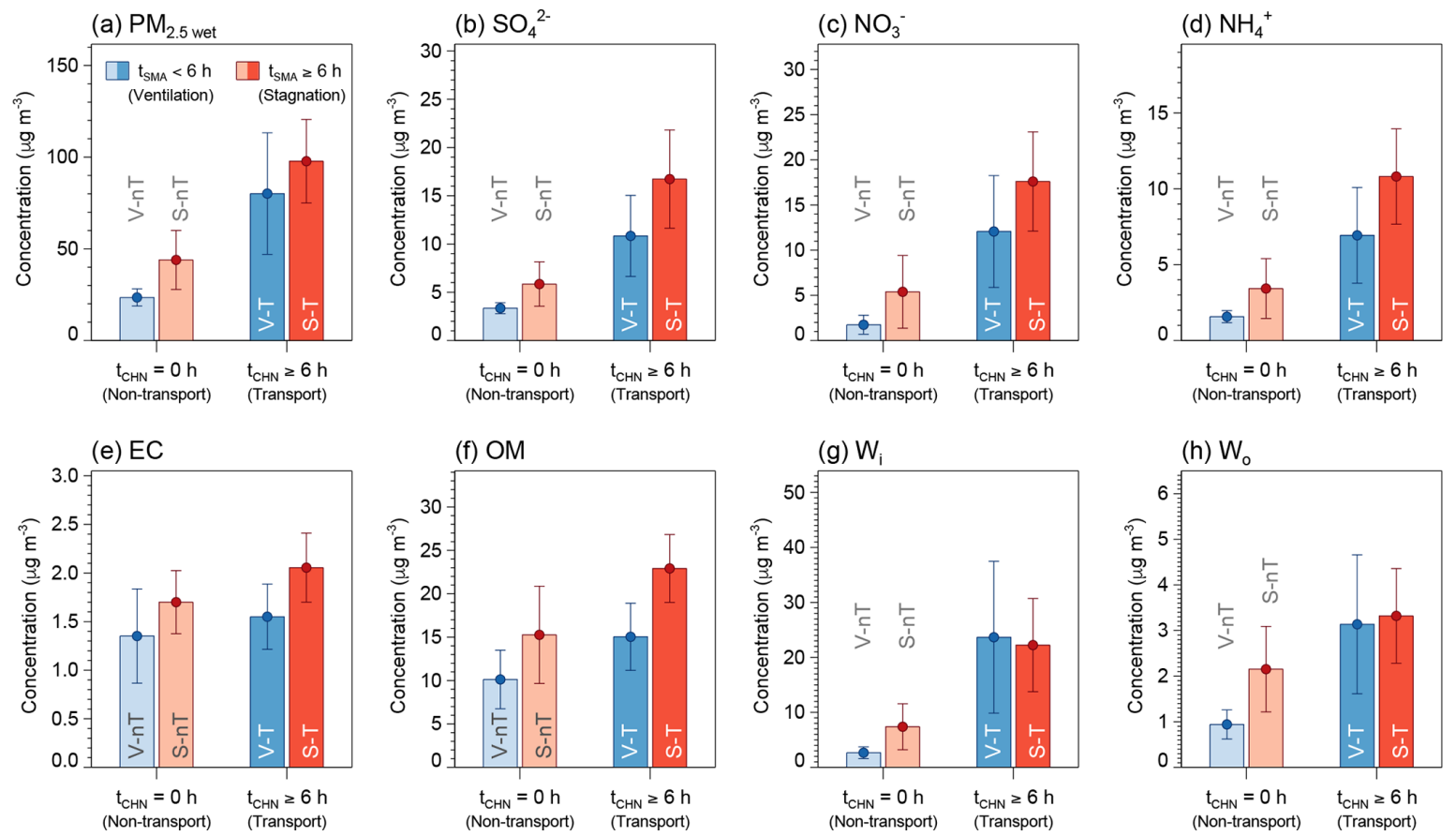

Figure 6. Average concentrations and confidence intervals at $95 \%$ of (a) wet $\mathrm{PM}_{2.5}\left(\mathrm{PM}_{2.5}\right.$ wet $)$, (b) sulfate $\left(\mathrm{SO}_{4}^{2-}\right)$, (c) nitrate $\left(\mathrm{NO}_{3}^{-}\right)$, (d) ammonium $\left(\mathrm{NH}_{4}^{+}\right)$, (e) elemental carbon (EC), (f) organic matter $(\mathrm{OM})$, (g) inorganic ALW ( $\left.W_{\mathrm{i}}\right)$, and (h) organic ALW ( $\left.W_{\mathrm{o}}\right)$ for the "local ventilation with no regional transport" (V-nT) group (light blue), "local stagnation with no regional transport" (S-nT) group (light red), "local ventilation with regional transport" (V-T) group (darker light blue), and "local stagnation with regional transport" (S-T) group (darker light red) categorized by ranges of the average daily residence time of backward trajectories in the Seoul metropolitan area $\left(t_{\mathrm{SMA}}\right)$ and in the North China Plain and Yangtze River Delta $\left(t_{\mathrm{CHN}}\right)$.

dation (e.g., from $\mathrm{NO}_{x}$ to $\mathrm{HNO}_{3}$ ) or partitioning of inorganic species into the particle phase.

Note that OM concentration seems to be increased by both effects of regional transport and local stagnation (Table 2 and Fig. 6f). However, the average estimates of the $\mathrm{O} / \mathrm{C}$ ratio $(\sim 0.55)$ and $\mathrm{OM} / \mathrm{OC}$ ratio $(\sim 1.87)$, which are in between semi-volatile oxygenated OA (SV-OOA) and lowvolatility oxygenated OA (LV-OOA), are similar for the four categorized groups (Table 2). Together with weak correlations of the $\mathrm{O} / \mathrm{C}$ ratio with wind speed $(r=-0.093)$ and BLH $(r=-0.172)$ in total daily data $(n=118)$, this suggests that aging and oxidation of SOA in Seoul was not much dependent on external conditions like stagnation or transport. Rather, significant correlations of the $\mathrm{O} / \mathrm{C}$ ratio with temperature $(r=-0.531)$ and solar irradiance $(r=-0.370)$ indicate the winter-high/summer-low seasonality of the secondary fraction in OA. Such temperature-dependent SOA fraction can be also found in OC/EC ratio $(r=-0.638$ for temperature and $r=-0.469$ for solar irradiance), which can be regarded as an index for secondary OC, and is consistent with partitioning theory (Takekawa et al., 2003).

\subsection{Fractional changes of ALW and SIA by effects of regional transport and local stagnation}

The chemical mass fraction of $\mathrm{PM}_{2.5}$ is expected to be affected by source characteristics (emissions) and chemical process (secondary aerosol formation), but not by the physical and dynamical processes (transport and accumulation), which affect the mass concentration of $\mathrm{PM}_{2.5}$. Thus, the mass fraction of each component is helpful to understand the source and chemical characteristics of each categorized group.

In terms of the component fraction, $\mathrm{PM}_{2.5}$ of the "local stagnation with regional transport" (S-T) group can be characterized by inorganic-rich, wet particles, while that of the "local ventilation with no regional transport" (V-nT) group was relatively organic-richer and drier (Fig. 7). Estimated wet $\mathrm{PM}_{2.5}$ (including ALW of both $W_{\mathrm{i}}$ and $W_{\mathrm{o}} ; \mathrm{PM}_{2.5}$ wet) of the S-T group contained larger fractions of SIA species $\left(\mathrm{SO}_{4}^{2-}, \mathrm{NO}_{3}^{-}\right.$, and $\left.\mathrm{NH}_{4}^{+}\right)$and $\mathrm{ALW}$ but a smaller OM fraction (46\% SIA, $23 \%$ OM, and $26 \%$ ALW) than that of the V-nT group (29\% SIA, $43 \%$ OM, and $15 \%$ ALW). Comparisons with the "local ventilation with regional transport" (V-T) group (37\% SIA, $19 \%$ OM, and $33 \%$ ALW) and the "local stagnation with no regional transport" (S-nT) group (34\% SIA, $35 \%$ OM, and $21 \%$ ALW) show that the effect 
of regional transport increases inorganic and water fractions, while the effect of local stagnation raises organic fraction of the total $\mathrm{PM}_{2.5}$ wet. Note that the increase in ALW fraction from the V-nT (15\%) to V-T (33\%) groups is much larger than that from the S-nT (21\%) to S-T (26\%) groups because of the significantly higher increase in $\mathrm{RH}$ from the $\mathrm{V}$-nT (46\%) to V-T (61\%) groups compared to that from the S-nT (54\%) to S-T (52\%) groups. The relationship between RH and ALW, as well as hygroscopic properties of Seoul haze particles, will be further discussed in the next section.

The $\mathrm{SO}_{4}^{2-}$ fraction of dry $\mathrm{PM}_{2.5}$ (excluding $W_{\mathrm{i}}$ and $W_{\mathrm{o}}$; $\mathrm{PM}_{2.5}$ dry) was $\sim 17 \%$ for the no regional-transport (V-nT and S-nT) groups and about $20 \%$ and $23 \%$ for the V-T and S-T groups, respectively. The $\mathrm{SO}_{4}^{2-}$ fraction in the no regional-transport groups is close to the background fraction of $\mathrm{SO}_{4}^{2-}$ in $\mathrm{PM}_{2.5}$ dry in Seoul, and this fraction is comparable to the "local sulfate source" contribution of $21.7 \%$ (mostly in the form of ammonium sulfate and equivalent to the $\mathrm{SO}_{4}^{2-}$ contribution of $\sim 16 \%$ ) identified by the previous source apportionment study on $\mathrm{PM}_{2.5}$ in Seoul (Kim et al., 2016). A previous field study conducted on the multiday haze episode showed that the $\mathrm{SO}_{4}^{2-}$ concentration at the upwind background site over the Yellow Sea (Deokjeok Island; $37.233^{\circ} \mathrm{N}, 126.149^{\circ} \mathrm{E}$ ) was nearly the same as Seoul $\mathrm{SO}_{4}^{2-}$ at the regional-transport stage of haze or the clean period and even kept $\sim 50 \%$ of the Seoul $\mathrm{SO}_{4}^{2-}$ concentration at the local-stagnation stage of the haze episode (Seo et al., 2017). Thus, together with considering the small $\mathrm{SO}_{2}$ emission in the Seoul metropolitan area compared to the North China Plain (Li et al., 2017; NIER, 2018) and the $\mathrm{SO}_{2}$ increase through the regional-transport effect (regionaltransport groups minus no regional-transport groups; $\sim 2-$ $4 \mathrm{ppb}$ ), the majority of $\mathrm{SO}_{4}^{2-}$ in the regional-transport (V-T and S-T) groups seems to be directly transported from China or produced during the transport from China before arriving at the Seoul metropolitan area.

The $\mathrm{NO}_{3}^{-}$fraction of $\mathrm{PM}_{2.5}$ dry was only $\sim 9 \%$ for the $\mathrm{V}-\mathrm{nT}$ group but increased to $16 \%$ and $23 \%$ for the S$\mathrm{nT}$ and V-T groups and reached more than $24 \%$ for the $\mathrm{S}-\mathrm{T}$ group. Interestingly, the fractional increase through the local-stagnation effect (local-stagnation groups minus local-ventilation groups; $\sim 2 \%-7 \%$ ) is much smaller than that through the regional-transport effect (regional-transport groups minus no regional-transport groups; 9\%-14\%) despite the same increase in $\mathrm{NO}_{2}$ concentration $(\sim 15 \mathrm{ppb}$; Table 2) through two different effects. Seoul is one of the largest sources of $\mathrm{NO}_{x}$ in Korea, but the previous study using satellite $\mathrm{NO}_{x}$ column data with the Lagrangian model demonstrated that the Chinese contribution to the $\mathrm{NO}_{2}$ columns over Korea reaches up to $\sim 50 \%-70 \%$ (Lee et al., 2014). However, the impact of regional transport on the increase in $\mathrm{NO}_{3}^{-}$fraction, which is $\sim 2$ times higher than that of the local stagnation, indicates a nonlinear effect of regional transport on the $\mathrm{NO}_{3}^{-}$increase in Seoul haze.
The $\mathrm{NH}_{4}^{+}$fraction of $\mathrm{PM}_{2.5}$ dry was $8 \%$ for the $\mathrm{V}-\mathrm{nT}$ group, $10 \%$ for the S-nT group, $13 \%$ for the V-T group, and $15 \%$ for the S-T group. The higher fractional increase in $\mathrm{NH}_{4}^{+}$through the regional-transport effect (T-minus nTgroups; $5 \%$ ) compared to that through the local-stagnation effect (S-minus V-groups; $2 \%$ ) results from the higher increase in both $\mathrm{SO}_{4}^{2-}$ and $\mathrm{NO}_{3}^{-}$aerosols related to the regional-transport effect.

\subsection{Synergistic effect of transported hygroscopic particles on SIA in the cold season}

The high-concentration, inorganic-rich, and wet particles (high SIA and ALW fractions of $\mathrm{PM}_{2.5}$ wet) mostly belong to the regional-transport (V-T and S-T) groups, of which backward trajectories originated from the upwind regional source area (the North China Plain and Yangtze River Delta), while relatively low-concentration, organic-rich dry particles (high $\mathrm{OM}$ fraction of $\mathrm{PM}_{2.5}$ wet) belong to the "local ventilation with no regional transport" (V-nT) group (Fig. 8a and b). The ALW fraction is a function of $\mathrm{RH}$ and also increases with the SIA fraction at the same RH (Fig. 8c), similar to the Beijing haze (Wu et al., 2018). This indicates that Seoul haze is hygroscopic and the major driver of its hygroscopicity is inorganic species. Since the SIA fraction was relatively higher in the regional-transport groups compared to that in the no regional transport groups, the hygroscopic properties of $\mathrm{PM}_{2.5}$ in Seoul were more clearly revealed in the regionaltransport groups (Fig. 8d). Therefore, the ALW fraction in the transported particles (e.g., the regional-transport groups) was higher than that in the particles of local origin (e.g., the "local stagnation with no regional transport" (S-nT) group).

The concentrations of $\mathrm{SO}_{4}^{2-}, \mathrm{NO}_{3}^{-}$, and $\mathrm{NH}_{4}^{+}$increase with their gas-phase precursors $\left(\mathrm{SO}_{2}, \mathrm{NO}_{2}\right.$, and $\left.\mathrm{NH}_{3}\right)$ in Seoul, except for the V-nT group. However, the regression slopes of the $\mathrm{SO}_{4}^{2-}, \mathrm{NO}_{3}^{-}$, and $\mathrm{NH}_{4}^{+}$with respect to their precursors in the regional-transport groups are steeper than the slope of the S-nT group (Fig. 9). Such a higher sensitivity of the increase in $\mathrm{SO}_{4}^{2-}, \mathrm{NO}_{3}^{-}$, and $\mathrm{NH}_{4}^{+}$to the gasphase precursors of the regional-transport groups is related to the higher ratios of sulfur oxidation (SOR) and partitioning $\left[\varepsilon\left(\mathrm{NO}_{3}^{-}\right)\right.$and $\left.\varepsilon\left(\mathrm{NH}_{4}^{+}\right)\right]$compared to the $\mathrm{S}-\mathrm{nT}$ group (Fig. 10b, f, and j). Since the average concentrations of total sulfur $\left(=\mathrm{SO}_{2}+\mathrm{SO}_{4}^{2-}\right)$, total $\mathrm{HNO}_{3}$, and total $\mathrm{NH}_{3}$ are highest in the "local stagnation with regional transport" (S-T) group due to a combination of remote precursors transported from China and local precursors accumulated in the stagnant condition (Fig. 10a, e, and i), the high SOR, $\varepsilon\left(\mathrm{NO}_{3}^{-}\right)$, and $\varepsilon\left(\mathrm{NH}_{4}^{+}\right)$of the regional-transport groups induced the highest average $\mathrm{SO}_{4}^{2-}, \mathrm{NO}_{3}^{-}$, and $\mathrm{NH}_{4}^{+}$concentrations of the $\mathrm{S}-\mathrm{T}$ group (Table 2).

The SOR, $\varepsilon\left(\mathrm{NO}_{3}^{-}\right)$, and $\varepsilon\left(\mathrm{NH}_{4}^{+}\right)$averaged for four range classes of temperature and inorganic $\operatorname{ALW}\left(W_{\mathrm{i}}\right)$ show that all the ratios increased with $W_{\mathrm{i}}$ (Fig. 10d, h, and $\left.\mathrm{l}\right)$, and $\varepsilon\left(\mathrm{NO}_{3}^{-}\right)$ and $\varepsilon\left(\mathrm{NH}_{4}^{+}\right)$decreased with temperature (Fig. $10 \mathrm{~g}$ and $\mathrm{k}$ ). 
(a) Ventilation + non-transport (V-nT) type
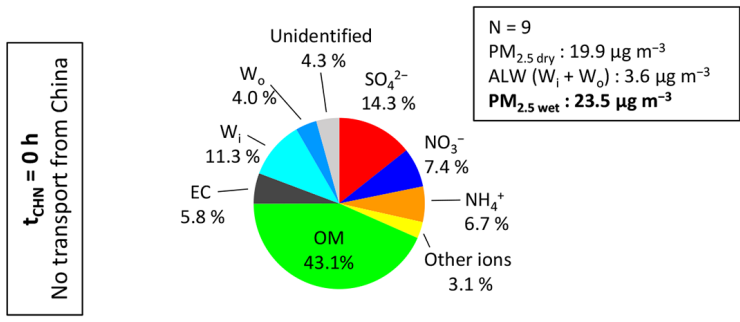

(c) Ventilation + transport (V-T) type

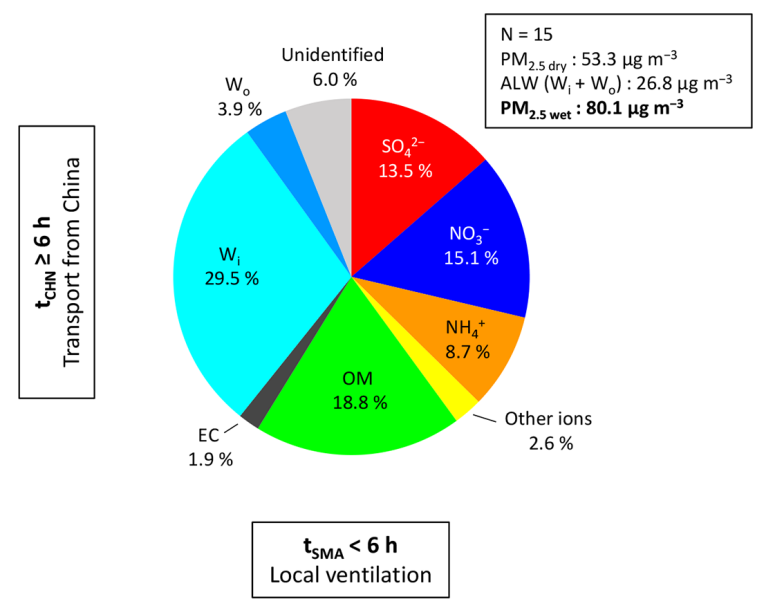

(b) Stagnation + non-transport (S-nT) type

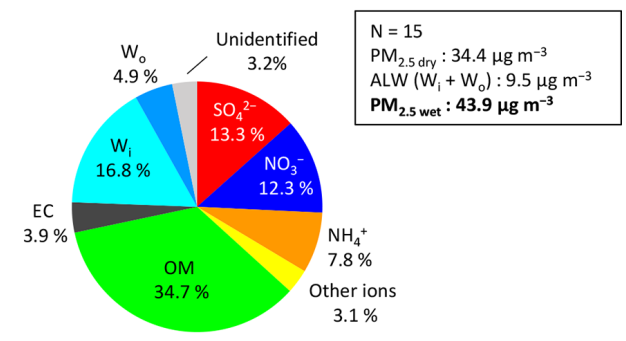

(d) Stagnation + transport (S-T) type

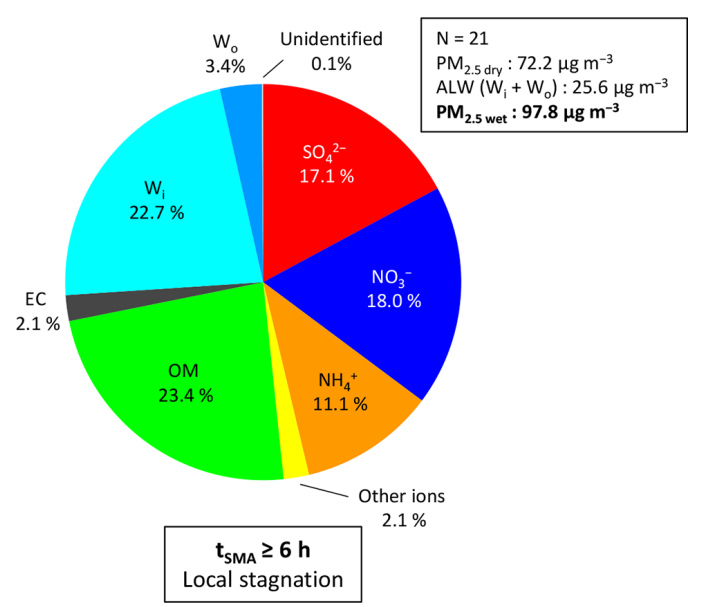

Figure 7. Average chemical compositions of wet $\mathrm{PM}_{2.5}\left(\mathrm{PM}_{2.5}\right.$ wet $)$ for the (a) "local ventilation with no regional transport" (V-nT) group, (b) "local stagnation with no regional transport" (S-nT) group, (c) "local ventilation with regional transport" (V-T) group, and (d) "local stagnation with regional transport” (S-T) group. Fractional species are sulfate (red), nitrate (dark blue), ammonium (orange), organic matter (green), elemental carbon (black), inorganic ALW (light blue), organic ALW (darker light blue), and other ions (chloride, sodium, potassium, magnesium, and calcium; yellow). The size of each circle is proportional to the $\mathrm{PM}_{2.5}$ wet concentration.

Changes in $W_{\mathrm{i}}$ from the $\mathrm{S}$-nT group $\left(\sim 7 \mu \mathrm{g} \mathrm{m}^{-3}\right.$ on average; $\left.W_{\mathrm{i} 1}\right)$ to the regional-transport groups $\left(>20 \mu \mathrm{g} \mathrm{m} \mathrm{m}^{-3}\right.$ on average; $\left.W_{\mathrm{i} 3}\right)$ increase $\mathrm{SOR}, \varepsilon\left(\mathrm{NO}_{3}^{-}\right)$, and $\varepsilon\left(\mathrm{NH}_{4}^{+}\right)$by approximately up to $20 \%$ for each ratio. This implies that the transported haze particles in the regional-transport groups, which are richer in inorganics and more hygroscopic than the local haze particles of the S-nT group (Fig. 8), promote SIA production. The aqueous-phase oxidation of $\mathrm{SO}_{2}$ via $\mathrm{H}_{2} \mathrm{O}_{2}, \mathrm{O}_{3}$, $\mathrm{NO}_{2}$, and transition metal ion (TMI) pathways (Harris et al., 2013; Cheng et al., 2016; Wang et al., 2016) and the partitioning of $\mathrm{HNO}_{3}$ and $\mathrm{NH}_{3}$ via dissolution and dissociation in the wet particles (Seinfeld and Pandis, 2016) are effective ways to produce $\mathrm{SO}_{4}^{2-}, \mathrm{NO}_{3}^{-}$, and $\mathrm{NH}_{4}^{+}$. Therefore, ALW in the hygroscopic particles can synergistically increase the inorganic species in a precursor-rich urban area like Seoul.

In terms of the synergistic increase in $\mathrm{NO}_{3}^{-}$with $\mathrm{ALW}$, the ratio between $\mathrm{NO}_{3}^{-}$and $\mathrm{SO}_{4}^{2-}$ can be an important factor. Hygroscopic uptake of ALW by both $\mathrm{SO}_{4}^{2-}$ and $\mathrm{NO}_{3}^{-}$ can increase $\mathrm{pH}$ through a dilution effect on hydrogen ions $\left(\mathrm{H}^{+}\right)$. Because $\mathrm{NO}_{3}^{-}$is a semi-volatile hygroscopic species, the higher $\mathrm{pH}$ increased by ALW allows more partitioning of $\mathrm{HNO}_{3}$ gas into the particle phase and takes up more $\mathrm{ALW}$. However, if $\mathrm{SO}_{4}^{2-}$ is dominant in the particle, such a feedback process will be weakened because $\mathrm{SO}_{4}^{2-}$ is nonvolatile (Guo et al., 2017). The average $\mathrm{NO}_{3}^{-}$-to- $\mathrm{SO}_{4}^{2-}$ molar ratios of the regional-transport groups (1.87 for the S-T group and 1.60 for the V-T group) are higher than that of the no regional-transport groups (1.29 for the $\mathrm{S}-\mathrm{nT}$ group and 0.81 for the V-nT group). Since ALW, $\mathrm{pH}$, and $\varepsilon\left(\mathrm{NO}_{3}^{-}\right)$in the regional-transport (V-T and S-T) groups are higher than those in the no regional-transport (V-nT and S-nT) groups, this feedback process can explain the synergistic effect of transported particles on the high $\mathrm{NO}_{3}^{-}$and $\mathrm{ALW}$ fractions.

Note that the partitioning of $\mathrm{HNO}_{3}$ and $\mathrm{NH}_{3}$ is also dependent on temperature (T) (Fig. $10 \mathrm{~g}$ and k). Changes in $T$ from the S-nT group $\left(\sim 15^{\circ} \mathrm{C}\right.$ on average; $\left.T_{3}\right)$ to the regional-transport groups $\left(\sim 9^{\circ} \mathrm{C}\right.$ on average; $\left.T_{2}\right)$ can also increase $\varepsilon\left(\mathrm{NO}_{3}^{-}\right)$and $\varepsilon\left(\mathrm{NH}_{4}^{+}\right)$by approximately $20 \%$ for each, similar to the effect of inorganic ALW. In Korea, the regional transport of air pollutants from the NCP area is usually accompanied by westerly or northwesterly continental outflow, which induces cold advection, during the cold season 

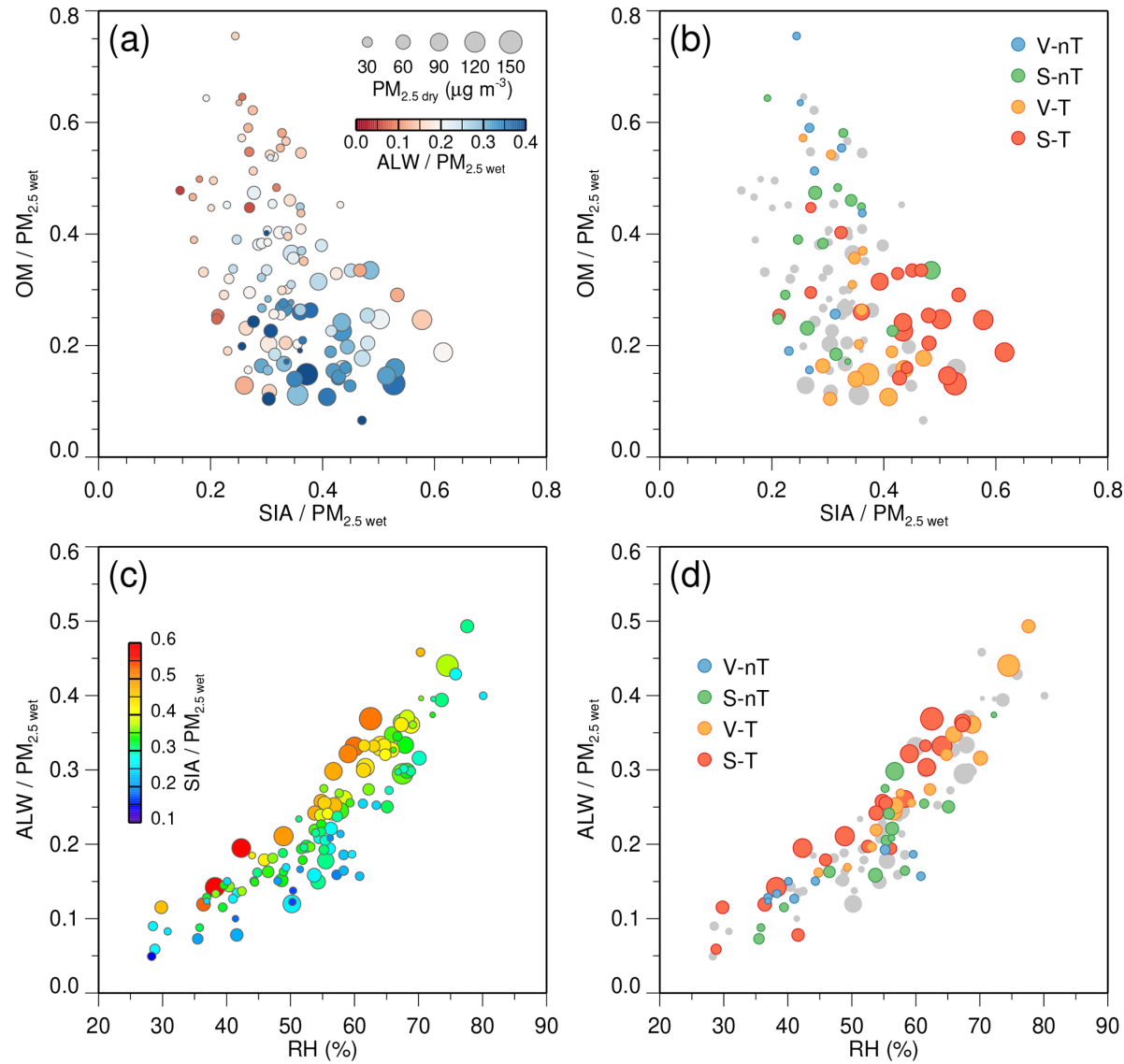

Figure 8. (a-b) Scatterplots of the secondary inorganic aerosol (SIA) fraction to wet $\mathrm{PM}_{2.5}\left(\mathrm{SIA} / \mathrm{PM}_{2.5}\right.$ wet $)$ ratio versus the organic matter $(\mathrm{OM})$ fraction to wet $\mathrm{PM}_{2.5}\left(\mathrm{OM} / \mathrm{PM}_{2.5}\right.$ wet $)$ ratio, colored according to (a) the aerosol liquid water (ALW) to wet $\mathrm{PM}_{2.5}(\mathrm{ALW} / \mathrm{PM} 2.5$ wet $)$ ratio and (b) the categories for each case. (c-d) Scatterplots of ALW/ $\mathrm{PM}_{2.5}$ wet versus relative humidity (RH), colored according to (c) SIA/ $\mathrm{PM}_{2.5}$ wet ratio and (d) the categories. The size of each circle is proportional to the dry $\mathrm{PM}_{2.5}\left(\mathrm{PM}_{2.5}\right.$ dry $)$ concentration.
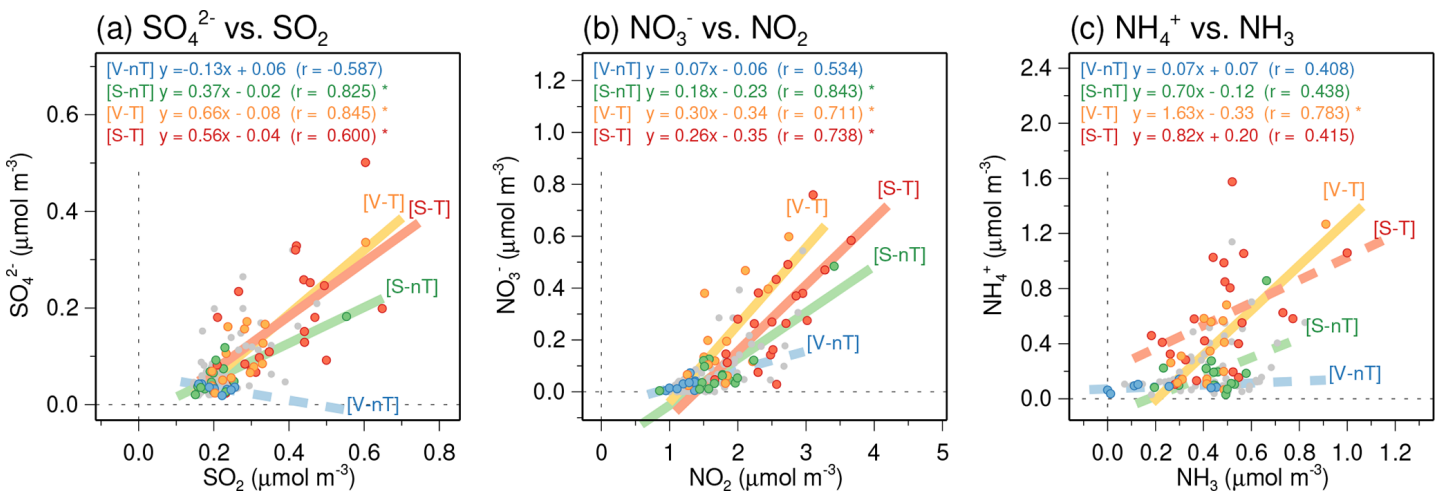

Figure 9. Scatterplots of (a) $\mathrm{SO}_{4}^{2-}$ versus $\mathrm{SO}_{2}$, (b) $\mathrm{NO}_{3}^{-}$versus $\mathrm{NO}_{2}$, and (c) $\mathrm{NH}_{4}^{+}$versus the reconstructed ammonia $\left(\mathrm{NH}_{3}\right)$. Filled circles in blue, green, yellow, and red colors represent daily data belonging to the "local ventilation with no regional transport" (V-nT) group, "local stagnation with no regional transport" (S-nT) group, "local ventilation with regional transport" (V-T) group, and "local stagnation with regional transport" (S-T) group, respectively. The statistically significant linear regression slopes $(p<0.01)$ for each group are represented by solid lines. 
(a) Total S

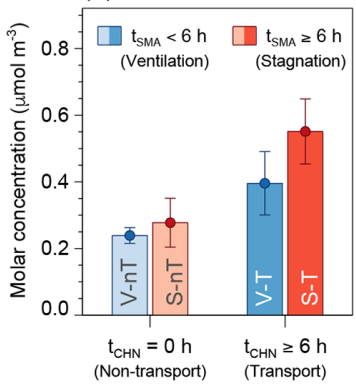

(e) Total $\mathrm{HNO}_{3}$

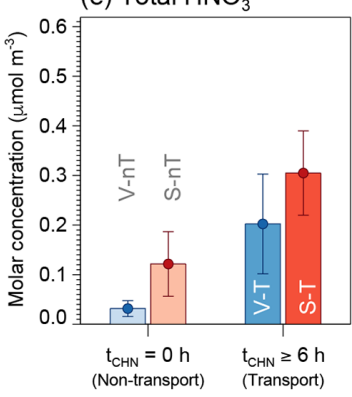

(i) Total $\mathrm{NH}_{3}$

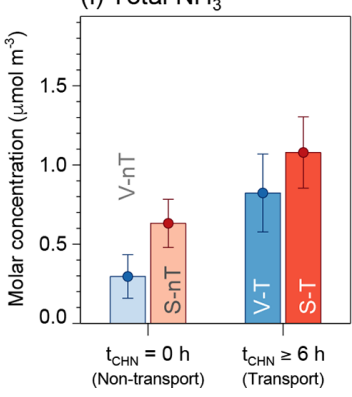

(b) SOR

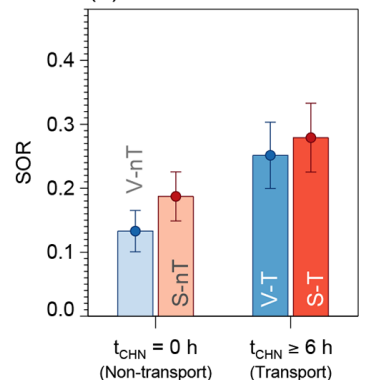

(f) $\varepsilon\left(\mathrm{NO}_{3}{ }^{-}\right)$

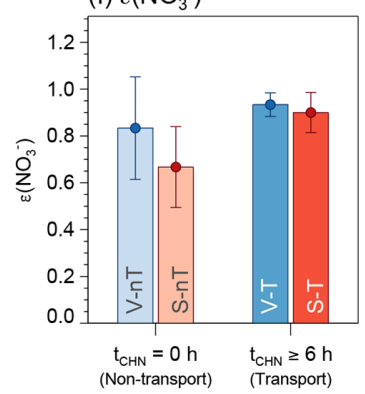

(j) $\varepsilon\left(\mathrm{NH}_{4}{ }^{+}\right)$

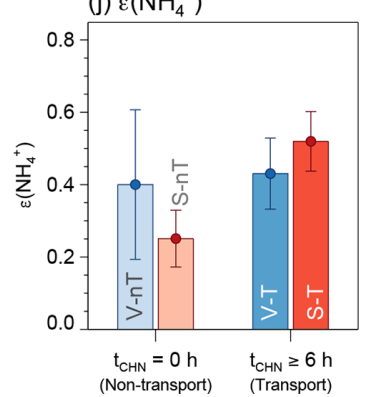

(c) SOR vs. T

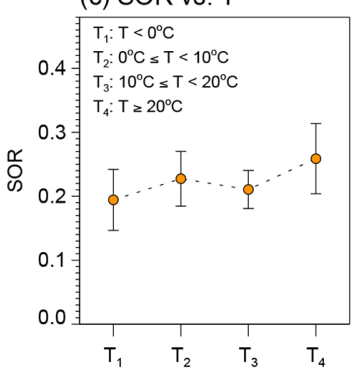

(g) $\varepsilon\left(\mathrm{NO}_{3}{ }^{-}\right)$vs. T

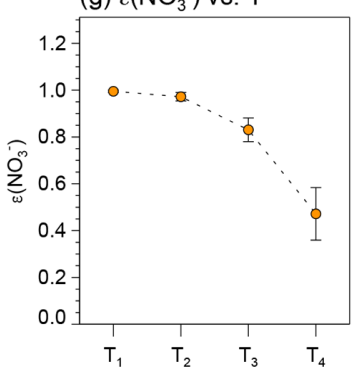

(k) $\varepsilon\left(\mathrm{NH}_{4}^{+}\right)$vs. T

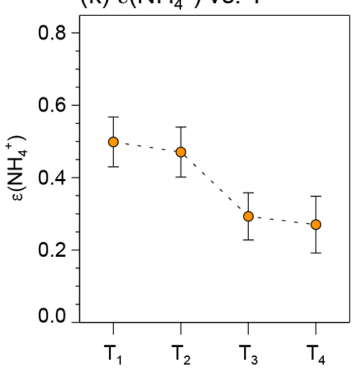

(d) SOR vs. W

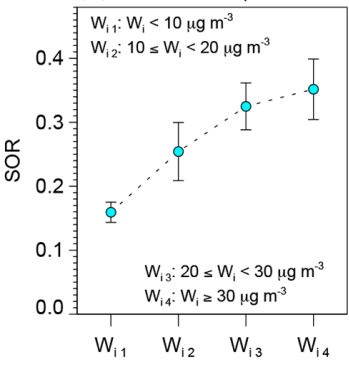

(h) $\varepsilon\left(\mathrm{NO}_{3}{ }^{-}\right)$vs. $\mathrm{W}_{\mathrm{i}}$

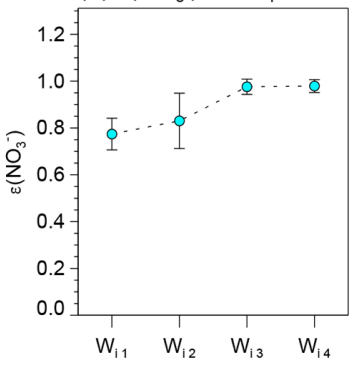

(I) $\varepsilon\left(\mathrm{NH}_{4}^{+}\right)$vs. W

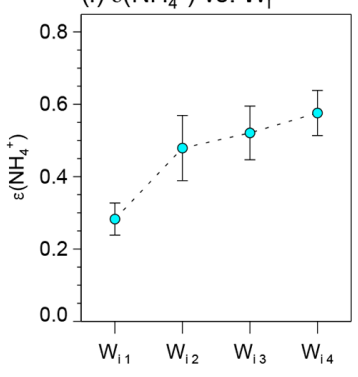

Figure 10. Average concentrations and confidence intervals at $95 \%$ of (a) total sulfur ( $\left.=\mathrm{SO}_{2}+\mathrm{SO}_{4}^{2-}\right)$, (b-d) sulfur oxidation ratio (SOR), (e) total $\mathrm{HNO}_{3}\left(=\mathrm{HNO}_{3}+\mathrm{NO}_{3}^{-}\right)$, (f-h) nitrate partitioning ratio $\left[\varepsilon\left(\mathrm{NO}_{3}^{-}\right)\right]$, (i) total $\mathrm{NH}_{3}\left(=\mathrm{NH}_{3}+\mathrm{NH}_{4}^{+}\right)$, and (j-l) ammonium partitioning ratio $\left[\varepsilon\left(\mathrm{NH}_{4}^{+}\right)\right]$. (a-b, e-f, $\left.\mathbf{i}-\mathbf{j}\right)$ Average for the "local ventilation with no regional transport" (V-nT) group (light blue), "local stagnation with no regional transport" (S-nT) group (light red), "local ventilation with regional transport" (V-T) group (darker light blue), and "local stagnation with regional transport" (S-T) group (darker light red). (c, g, k) Average for the temperature $(T)$ ranges of $T<0{ }^{\circ} \mathrm{C}\left(T_{1} ; n=19\right)$, $0^{\circ} \mathrm{C} \leq T<10^{\circ} \mathrm{C}\left(T_{2} ; n=31\right), 10^{\circ} \mathrm{C} \leq T<20^{\circ} \mathrm{C}\left(T_{3} ; n=30\right)$, and $T \geq 20^{\circ} \mathrm{C}\left(T_{4} ; n=19\right)$. (d, h, l) Average for the inorganic ALW $\left(W_{\mathrm{i}}\right)$ ranges of $W_{\mathrm{i}}<10 \mu \mathrm{g} \mathrm{m}^{-3}\left(W_{\mathrm{i} 1} ; n=58\right), 10 \mu \mathrm{gm}^{-3} \leq W_{\mathrm{i}}<20 \mu \mathrm{g} \mathrm{m}{ }^{-3}\left(W_{\mathrm{i} 2} ; n=14\right), 20 \mu \mathrm{gm}^{-3} \leq W_{\mathrm{i}}<30 \mu \mathrm{g} \mathrm{m}{ }^{-3}\left(W_{\mathrm{i} 3} ; n=12\right)$, and $W_{\mathrm{i}} \geq 30 \mu \mathrm{g} \mathrm{m}{ }^{-3}\left(W_{\mathrm{i} 4} ; n=15\right)$.

(Kim et al., 2018). The lower temperature of the $\mathrm{S}-\mathrm{T}$ group $\left(\sim 9{ }^{\circ} \mathrm{C}\right)$ compared to the S-nT group $\left(\sim 15^{\circ} \mathrm{C}\right)$ could lead to the higher sensitivity of the SIA increase to the precursor concentrations in the S-T group (Fig. 9). Interestingly, the increasing SOR through temperature (and also irradiance) is not as significant as that through inorganic ALW (Figs. 10c) despite the high-temperature and strong-irradiance conditions conducive to photochemical oxidation of $\mathrm{SO}_{2}$ in summer. This implies that the observed high $\mathrm{SO}_{4}^{2-}$ in the $\mathrm{S}-\mathrm{T}$ group resulted not only from the photochemical gas-phase oxidation but also considerably from the aqueous-phase oxidation of $\mathrm{SO}_{2}$ in the transported wet particles.

\subsection{Effect of $\mathrm{NO}_{x}$ and $\mathrm{NH}_{3}$ control on mitigating haze pollution in Seoul}

The $\varepsilon\left(\mathrm{NO}_{3}^{-}\right)$can be analytically calculated according to the solubility and dissociation of gas-phase $\mathrm{HNO}_{3}$ and represented as a sigmoid function ( $\mathrm{S}$ curve) of $\mathrm{pH}$ (Guo et al., 2018; Nah et al., 2018) by the following equation:

$$
\begin{aligned}
& \varepsilon\left(\mathrm{NO}_{3}^{-}\right)= \\
& \frac{H_{\mathrm{HNO}_{3}^{*}} W_{\mathrm{i}} R T\left(0.987 \times 10^{-14}\right)}{\gamma_{\mathrm{H}^{+}} \gamma_{\mathrm{NO}_{3}^{-}} 10^{-\mathrm{pH}}+H_{\mathrm{HNO}_{3}^{*}} W_{\mathrm{i}} R T\left(0.987 \times 10^{-14}\right)},
\end{aligned}
$$


where $0.987 \times 10^{-14}$ is the unit conversion factor from atmospheric pressure and micrograms to SI units, $R$ is the gas constant $\left(8.314 \mathrm{~J} \mathrm{~mol}^{-1} \mathrm{~K}^{-1}\right), W_{\mathrm{i}}\left(\mu \mathrm{g} \mathrm{m}^{-3}\right)$ is the ALW content associated with inorganic species, and $\mathrm{H}_{\mathrm{HNO}_{3}^{*}}$ is the effective Henry's law constant (products of Henry's law constant for $\mathrm{HNO}_{3}$ gases and the acid dissociation constant for $\mathrm{HNO}_{3} \leftrightarrow \mathrm{NO}_{3}^{-}+\mathrm{H}^{+}$) dependent on temperature and $\mathrm{pH}$ $\left(\mathrm{mol}^{2} \mathrm{~kg}^{-2} \mathrm{~atm}^{-1}\right.$ on a molality basis; Clegg et al., 1998). The product of activity coefficients, $\gamma_{\mathrm{H}^{+}} \gamma_{\mathrm{NO}_{3}^{-}}$, is dependent on both temperature and ionic strength (Kusik and Meissner, 1978; Kim et al., 1993). In this study, daily $\gamma_{\mathrm{H}^{+}} \gamma_{\mathrm{NO}_{3}^{-}}$was obtained based on daily average ambient temperature and ionic strength from ISORROPIA II and ranged from 0.135 to 0.734 , with an average of $0.333 \pm 0.150$.

The $\mathrm{S}$ curve of $\varepsilon\left(\mathrm{NO}_{3}^{-}\right)$as a function of $\mathrm{pH}$ is useful for examining the role of inorganic ALW and temperature in $\mathrm{HNO}_{3}-\mathrm{NO}_{3}^{-}$partitioning and provides insights into the potential $\mathrm{HNO}_{3}$ partitioning by a change in particle $\mathrm{pH}$. In Fig. 11, both a decrease in temperature and an increase in ALW can shift the $\varepsilon\left(\mathrm{NO}_{3}^{-}\right)$curves toward a lower $\mathrm{pH}$, so more $\mathrm{HNO}_{3}$ can exist in the particle phase. Almost $100 \%$ of the total $\mathrm{HNO}_{3}$ exists in the particle phase at the higher $\mathrm{pH}$ ( $>4$ ) in Seoul. Since the gas-phase $\mathrm{HNO}_{3}$ largely formed by the reaction of $\mathrm{NO}_{2}$ with hydroxyl radicals $(\mathrm{OH})$ is highly water-soluble (Seinfeld and Pandis, 2016), the transported wet particles (the regional-transport (V-T and S-T) groups) can easily take up $\mathrm{HNO}_{3}$ gas into the aerosol solution in the $\mathrm{NO}_{x}$-rich $(\sim 60 \mathrm{ppb})$ environment of Seoul (Vellingiri et al., 2015), particularly during the cold season. Note that ALW can additionally enhance the nitrate radical $\left(\mathrm{NO}_{3}\right)$ $\mathrm{N}_{2} \mathrm{O}_{5}$ pathway and heterogeneous $\mathrm{N}_{2} \mathrm{O}_{5}$ hydrolysis (Bertram et al., 2009). In addition, the high $\mathrm{NH}_{3}$ level $(\sim 10 \mathrm{ppb})$ in Seoul (Phan et al., 2013) helps further to increase the uptake of $\mathrm{HNO}_{3}$ gas into the aerosol solution (Guo et al., 2018).

To reduce ammonium nitrate aerosols in Seoul, therefore, two ways can be suggested; the $\mathrm{NO}_{x}$ control and the $\mathrm{NH}_{3}$ control. As shown in Fig. 9b, the observed $\mathrm{NO}_{3}^{-}$concentration is highly correlated with the $\mathrm{NO}_{2}$ level, and this implies that the $\mathrm{NO}_{x}$ control will be an effective way to reduce total $\mathrm{HNO}_{3}$ and $\mathrm{NO}_{3}^{-}$concentrations. Such a direct relationship between $\mathrm{NO}_{x}$ control and nitrate aerosol is significant at the condition of $\varepsilon\left(\mathrm{NO}_{3}^{-}\right)$close to 1 . Because of the higher $\varepsilon\left(\mathrm{NO}_{3}^{-}\right)$of the transported wet particles, the $\mathrm{NO}_{x}$ reduction will more effectively reduce $\mathrm{NO}_{3}^{-}$in the regional-transport groups compared to the "local stagnation with no regional transport" (S-nT) group. For example, the potential $\mathrm{NO}_{3}^{-}$reduction by a $10 \mathrm{ppb}$ decrease in ambient $\mathrm{NO}_{2}$ concentration deduced from the linear regression in Fig. $9 \mathrm{~b}$ can be estimated as being $\sim 8 \mu \mathrm{g} \mathrm{m}^{-3}$ for the "local ventilation with regional transport" (V-T) group, $\sim 7 \mu \mathrm{g} \mathrm{m}^{-3}$ for the "local stagnation with regional transport" (S-T) group, and $\sim 5 \mu \mathrm{g} \mathrm{m}^{-3}$ for the "local stagnation with no regional transport" (S-nT) group. On the other hand, the $\mathrm{NH}_{3}$ control to achieve the low $\varepsilon\left(\mathrm{NO}_{3}^{-}\right)$by lowering the particle $\mathrm{pH}$ from the current level

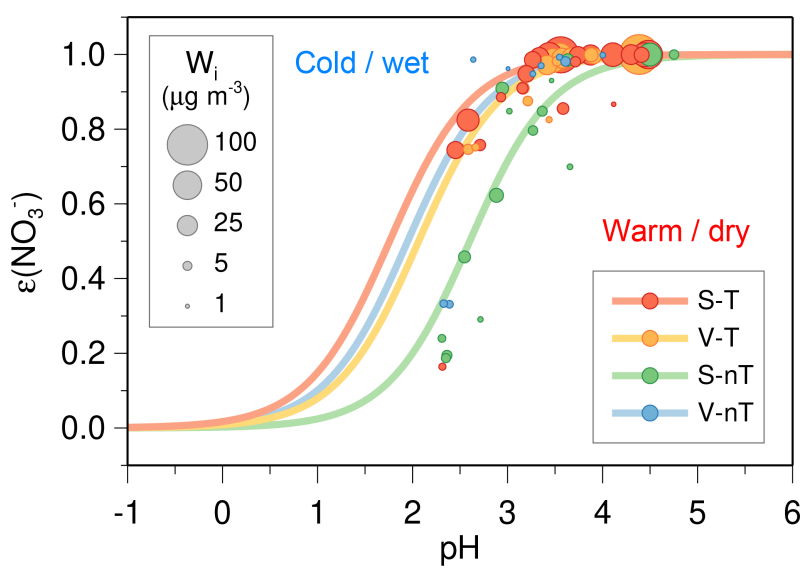

Figure 11. The calculated sigmoid curves ( $S$ curves) and observed ambient gas-particle partitioning ratios (solid circles) for nitrate $\left[\varepsilon\left(\mathrm{NO}_{3}^{-}\right)\right]$plotted against the ISORROPIA-predicted particle $\mathrm{pH}$. The blue, green, yellow, and red circles represent the "local ventilation with no regional transport" (V-nT) group, "local stagnation with no regional transport" (S-nT) group, "local ventilation with regional transport" (V-T) group, and "local stagnation with regional transport" (S-T) group, respectively, and the size of each circle is proportional to the concentration of inorganic ALW $\left(W_{\mathrm{i}}\right)$. The curves were calculated based on the median values of temperature $(T), W_{\mathrm{i}}$, and the product of activity coefficient $\left(\gamma_{\mathrm{H}^{+}} \gamma_{\mathrm{NO}_{3}^{-}}\right)$for each group; $T=0.6^{\circ} \mathrm{C}, W_{\mathrm{i}}=2.2 \mu \mathrm{g} \mathrm{m}^{-3}$, and $\gamma_{\mathrm{H}^{+}} \gamma_{\mathrm{NO}_{3}^{-}}=0.146$ for the $\mathrm{V}-\mathrm{nT}$ group; $T=17.5^{\circ} \mathrm{C}, W_{\mathrm{i}}=$ $5.6 \mu \mathrm{g} \mathrm{m}^{-3}$, and $\gamma_{\mathrm{H}^{+}} \gamma_{\mathrm{NO}_{3}^{-}}=0.295$ for the S-nT group; $T=$ $11.6^{\circ} \mathrm{C}, W_{\mathrm{i}}=16.6 \mu \mathrm{gm}^{-3}$, and $\gamma_{\mathrm{H}^{+}} \gamma_{\mathrm{NO}_{3}^{-}}=0.458$ for the $\mathrm{V}-\mathrm{T}$ group; $T=6.9^{\circ} \mathrm{C}, W_{\mathrm{i}}=18.0 \mu \mathrm{g} \mathrm{m}^{-3}$, and $\gamma_{\mathrm{H}^{+}} \gamma_{\mathrm{NO}_{3}^{-}}=0.400$ for the $\mathrm{S}-\mathrm{T}$ group.

( $\mathrm{pH}$ of $\sim 3.5$ on average) for the S-T group may cost more than that for the S-nT group because the $\varepsilon\left(\mathrm{NO}_{3}^{-}\right)$in the S-nT group (green circles) starts to decrease rapidly at $\mathrm{pH}<3.5$, while that in the regional-transport groups (yellow circles for the V-T group and red circles for the S-T group) remains relatively high $(\sim 80 \%)$ at the lower $\mathrm{pH}(\sim 2.5)$ (Fig. 11). Since the haze pollution in Seoul usually becomes severe with the regional transport of hygroscopic wet particles (e.g., the S-T group), a greater reduction in the $\mathrm{NH}_{3}$ emissions should be required for the higher-concentration S-T group compared to the lower-concentration S-nT group. However, the benefit of reducing $\mathrm{PM}_{2.5}$ mass concentration by an $\mathrm{NH}_{3}$ control can be canceled out by the adverse effects of strong particle acidity on human health (Fang et al., 2017).

\section{Conclusions}

Based on $\mathrm{PM}_{2.5}$ chemical speciation, gaseous pollutants, and meteorological data in Seoul together with backward trajectory analysis, the present study investigated chemical compositions and characteristics of urban haze particles in the 


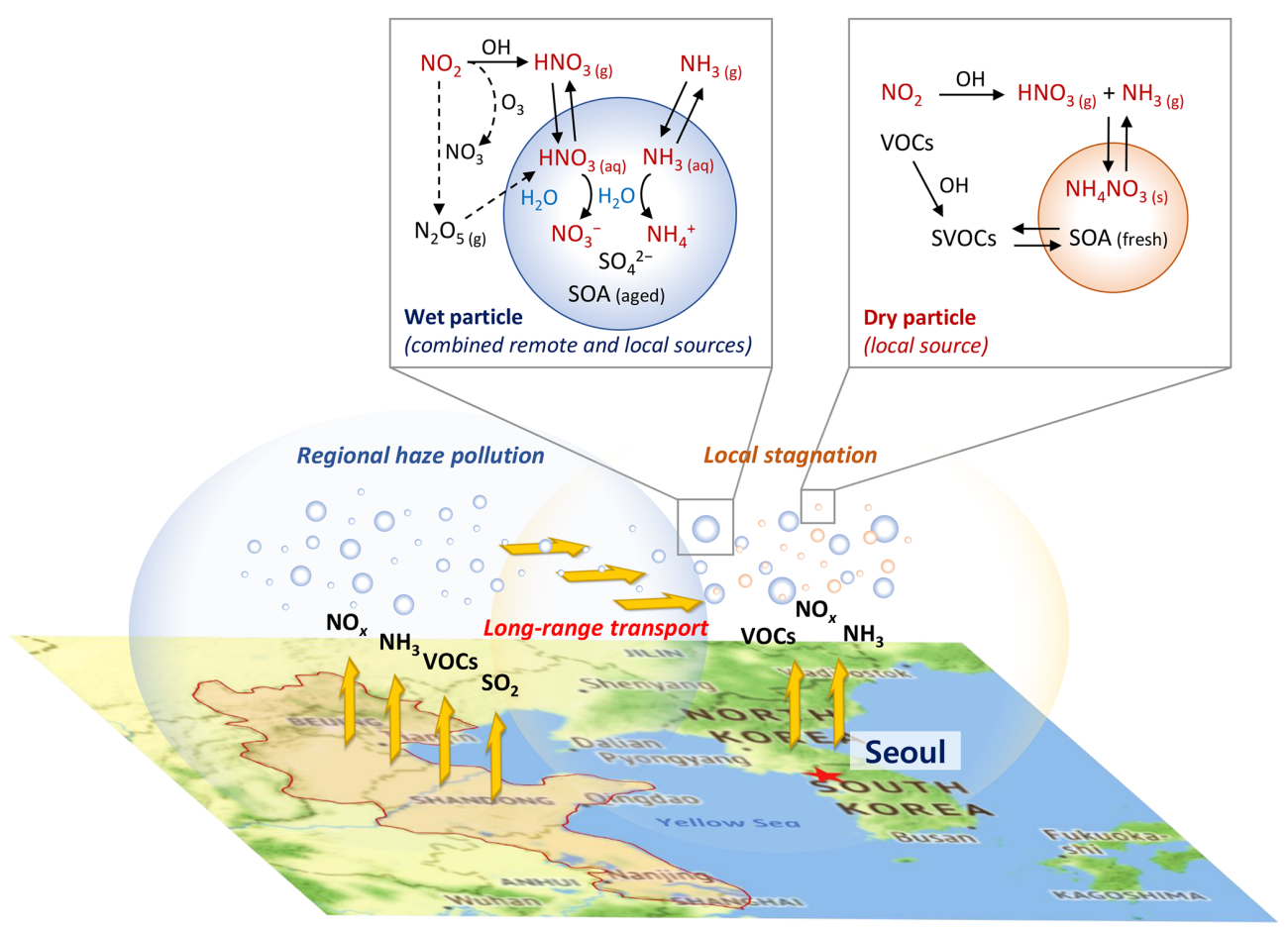

Figure 12. Schematic of synergistic nitrate partitioning to the particle phase aided by wet particles transported from the remote source area (North China Plain and Yangtze River Delta) in a high $\mathrm{NO}_{x}$ and $\mathrm{NH}_{3}$ urban area (Seoul metropolitan area) during the cold season in East Asia. The background map was derived from (C) Google Maps.

Asian continental outflow region, according to physical and dynamical conditions such as local stagnant condition in the urban area and regional transport of air pollutants from the remote source area. Although various factors like local emissions of primary pollutants and secondary precursors, atmospheric chemistry related to the secondary formation and aging of aerosols, and meteorological conditions can affect the urban haze pollution, a simple categorization by average residence times of backward trajectories within the local (Seoul metropolitan area) and remote (North China Plain and Yangtze River Delta) source areas showed clearly distinguishable characteristics in concentration and fractional composition of $\mathrm{PM}_{2.5}$ among the local-stagnation/ventilation groups and the regional-transport/non-transport groups. In particular, ALW content associated with inorganic species and particle $\mathrm{pH}$ estimated by the ISORROPIA II thermodynamic model helped to show different hygroscopic and inorganic partitioning properties of Seoul haze by the categorized groups.

The measurement group of "local stagnation with regional transport" (S-T) from China is characterized by higher $\mathrm{PM}_{2.5}$ concentration $\left(72 \pm 32 \mu \mathrm{g} \mathrm{m}^{-3}\right.$ of $\left.\mathrm{PM}_{2.5} \mathrm{dry}\right)$ and more inorganic-rich and wetter particles (46\% SIA, $23 \%$ OM, and $26 \%$ ALW in $\mathrm{PM}_{2.5}$ wet) in comparison to the measurement group of "local ventilation with no regional transport" (V$\mathrm{nT} ; 20 \pm 5 \mu \mathrm{g} \mathrm{m}^{-3}$ of $\mathrm{PM}_{2.5}$ dry and $29 \%$ SIA, $43 \% \mathrm{OM}$, and $15 \%$ ALW in $\mathrm{PM}_{2.5}$ wet). An increase in SIA from the "local ventilation with no regional transport" (V-nT) group to the "local stagnation with regional transport" (S-T) group $(\sim 7$ times from $\sim 7$ to $45 \mu \mathrm{g} \mathrm{m}^{-3}$ ) is larger than the OM increase ( $\sim 2$ times from 10 to $23 \mu \mathrm{g} \mathrm{m}^{-3}$ ) but relates closely to the increase in inorganic ALW $\left(\sim 7\right.$ times from $\sim 3$ to $\left.22 \mu \mathrm{g} \mathrm{m}^{-3}\right)$, indicating inorganic species as a major driver of hygroscopicity. The larger increase in SIA species $\left(\mathrm{SO}_{4}^{2-}\right.$ from $\sim 3$ to $17 \mu \mathrm{g} \mathrm{m}^{-3}$ and $\mathrm{NO}_{3}^{-}$from $\sim 2$ to $18 \mu \mathrm{g} \mathrm{m}^{-3}$ ) compared to the increase in gaseous precursors $\left(\mathrm{SO}_{2}\right.$ from 5 to $9 \mathrm{ppb}$ and $\mathrm{NO}_{2}$ from 27 to $57 \mathrm{ppb}$ ) suggests that there is not only the accumulation of local and transported particles but also additional chemical processes for the SIA production in the combination of regional transport and local stagnant conditions.

Further comparisons with the "local stagnation with no regional transport" (S-nT) group and the "local ventilation with regional transport" (V-T) group shows the stronger influence of regional transport rather than local stagnation on the high oxidation and partitioning ratios ( $\mathrm{SOR}, \varepsilon\left(\mathrm{NO}_{3}^{-}\right)$, and $\left.\varepsilon\left(\mathrm{NH}_{4}^{+}\right)\right)$associated with the SIA increase. SOR, $\varepsilon\left(\mathrm{NO}_{3}^{-}\right)$, and $\varepsilon\left(\mathrm{NH}_{4}^{+}\right)$were raised up to $\sim 20 \%$ by the increase in inorganic ALW in the Seoul haze condition, and this demonstrates an important role of ALW of the transported hygroscopic particles in increasing the SIA fraction. In addition, $\varepsilon\left(\mathrm{NO}_{3}^{-}\right)$and $\varepsilon\left(\mathrm{NH}_{4}^{+}\right)$are decreased through temperature, and thus the transported wet particles can efficiently convert the gas-phase $\mathrm{HNO}_{3}$ and $\mathrm{NH}_{3}$ into the particle-phase $\mathrm{NO}_{3}^{-}$and $\mathrm{NH}_{4}^{+}$during the cold season. Therefore, the synergistic ef- 
fect of transported wet particles and local precursors on the SIA increase and high $\mathrm{PM}_{2.5}$ concentration in Seoul can be most prominent in the cold season, when the continental outflow dominates East Asia and helps transboundary transport of air pollutants to Korea. Since $\mathrm{SO}_{2}$ emissions in Seoul are small, the increased $\mathrm{SO}_{4}^{2-}$ in the regional-transport condition is likely to be transported from the remote source areas in China or produced during the transport. On the other hand, the high- $\mathrm{NO}_{x}(\sim 60 \mathrm{ppb})$ and $\mathrm{NH}_{3}$-rich $(\sim 10 \mathrm{ppb})$ conditions in Seoul can promote the uptake of $\mathrm{HNO}_{3}$ into the wet particle.

Most of the severe haze events in Seoul occur in the local stagnant conditions combined with transport of the preceding regional haze (Seo et al., 2017). The transported regional haze particles with a high inorganic fraction and abundant ALW readily take up $\mathrm{HNO}_{3}$ and $\mathrm{NH}_{3}$ gases under the high $\mathrm{NO}_{x}$ and $\mathrm{NH}_{3}$ conditions of the urban area and consequently reduce the air quality more than local haze formation without regional transport (Fig. 12). Considering both the high $\varepsilon\left(\mathrm{NO}_{3}^{-}\right)$of the transported wet particles and the low $\mathrm{pH}$ required to decrease $\varepsilon\left(\mathrm{NO}_{3}^{-}\right)$in the combined regional-transport-local-stagnation condition, $\mathrm{NO}_{x}$ control rather than $\mathrm{NH}_{3}$ control may be a more effective $\mathrm{PM}_{2.5}$ reduction strategy in Seoul.

Our results provide insight into the nonlinear effects of the transported particles and local precursors on urban haze pollution in the regional air quality modeling system. For example, domestic and foreign contributions to $\mathrm{PM}_{10}$ concentration over the Seoul metropolitan area estimated by the brute force method approach show a discrepancy between reductions in domestic and foreign emissions, in particular during the cold season (Kim et al., 2017). The synergistic enhancement of urban haze pollution by the combination of regional and local sources makes a precise estimation of domestic and foreign contributions difficult. This study also shows a need for international cooperation in air quality management.

Code availability. The ISORROPIA II thermodynamic model (Fountoukis and Nenes, 2007) is available on the website of the Laboratory of atmospheric processes and their impacts (LAPI) in the EPFL (https://www.epfl.ch/labs/lapi/isorropia/ iso-code-repository/, last access: 25 June 2020). The HYSPLIT model (Stein et al., 2015) is available on the website managed by the NOAA Air Resources Laboratory (https://www.ready.noaa.gov/ HYSPLIT.php, last access: 25 June 2020).

Data availability. Daily $\mathrm{PM}_{2.5}$ measurements, chemical analysis, meteorological factors, and ISORROPIA II result data utilized in this study are available at https://drive.google.com/open?id= 1hJrwViP_qx23dTuBxLapbWhAn5LrTXMI (last access: 25 June 2020). The hourly data of $\mathrm{SO}_{2}, \mathrm{NO}_{2}, \mathrm{CO}, \mathrm{O}_{3}$, and $\mathrm{PM}_{10}$ concentrations at 34 air quality monitoring sites in Seoul for the analysis period are available on the website managed by the Korea Environment Corporation (2019; https://www.airkorea.or.kr/web/
last_amb_hour_data?pMENU_NO=123). The hourly meteorological data of temperature, sea level pressure, relative humidity, wind speed, and solar irradiance at the Seoul weather station for the same period can be found on the website of the KMA (2020; https:// data.kma.go.kr/data/grnd/selectAsosRltmList.do?pgmNo=36). The ERA-Interim data (Dee et al., 2011) can be accessed via the European Centre for Medium-Range Weather Forecasts (ECMWF) data server (http://apps.ecmwf.int/datasets/data/interim-full-daily/, last access: 25 June 2020).

Supplement. The supplement related to this article is available online at: https://doi.org/10.5194/acp-20-7575-2020-supplement.

Author contributions. JS initiated the investigation and performed thermodynamic modeling analyses. JS and YBL extensively discussed the concept. HCJ conducted the field measurement and provided chemical analyses. DY and JYK provided additional feedback on the paper. JS prepared the paper with contributions from all coauthors.

Competing interests. The authors declare that they have no conflict of interest.

Acknowledgements. This research was supported by the Korea Institute of Science and Technology (KIST) and the National Strategic Project - Fine Particle of the National Research Foundation of Korea (NRF) funded by the Ministry of Science and ICT (MSIT), the Ministry of Environment (ME), and the Ministry of Health and Welfare (MOHW) (2017M3D8A1090654). Yong Bin Lim was supported by NRF (2019M3D8A1070941). Daeok Youn was supported by the Basic Science Research Program through the National Research Foundation of Korea (NRF) funded by the Ministry of Education (MOE) (2015R1D1A3A01020130) and Korea Environment Industry \& Technology Institute (KEITI) funded by the Korea Ministry of Environment (ME) (2018001310004). The authors are grateful to the editor and two referees for their valuable and constructive comments and suggestions.

Financial support. This research has been supported by the National Strategic Project - Fine Particle of the National Research Foundation of Korea (NRF) funded by the Ministry of Science and ICT (MSIT), the Ministry of Environment (ME), and the Ministry of Health and Welfare (MOHW) (grant no. 2017M3D8A1090654), the National Research Foundation of Korea (NRF) (grant no. 2019M3D8A1070941), the Basic Science Research Program through the National Research Foundation of Korea (NRF) funded by the Ministry of Education (MOE) (grant no. 2015R1D1A3A01020130), and the Korea Environment Industry \& Technology Institute (KEITI) funded by the Ministry of Environment (ME) (grant no. 2018001310004). 
Review statement. This paper was edited by Barbara Ervens and reviewed by Rodney Weber and one anonymous referee.

\section{References}

Asa-Awuku, A., Nenes, A., Gao, S., Flagan, R. C., and Seinfeld, J. H.: Water-soluble SOA from Alkene ozonolysis: composition and droplet activation kinetics inferences from analysis of CCN activity, Atmos. Chem. Phys., 10, 1585-1597, https://doi.org/10.5194/acp-10-1585-2010, 2010.

Ashbaugh, L. L. and Eldred R. A.: Loss of particle nitrate from Teflon sampling filters: Effects on measured gravimetric mass in California and in the IMPROVE network, J. Air Waste Manage., 54, 93-104, https://doi.org/10.1080/10473289.2004.10470878, 2004.

Bertram, T. H., Thornton, J. A., Riedel, T. P., Middlebrook, A. M., Bahreini, R., Bates, T. S., Quinn, P. K., and Coffman, D. J.: Direct observations of $\mathrm{N}_{2} \mathrm{O}_{5}$ reactivity on ambient aerosol particles, Geophys. Res. Lett., 36, L19803, https://doi.org/10.1029/2009GL040248, 2009.

Birch, M. and Cary, R: Elemental carbon-based method for monitoring occupational exposures to particulate diesel exhaust, Aerosol Sci. Tech., 25, 221-241, https://doi.org/10.1080/02786829608965393, 1996.

Carlton, A. G. and Turpin, B. J.: Particle partitioning potential of organic compounds is highest in the Eastern US and driven by anthropogenic water, Atmos. Chem. Phys., 13, 10203-10214, https://doi.org/10.5194/acp-13-10203-2013, 2013.

Chang, R. Y.-W., Slowik, J. G., Shantz, N. C., Vlasenko, A., Liggio, J., Sjostedt, S. J., Leaitch, W. R., and Abbatt, J. P. D.: The hygroscopicity parameter $(\kappa)$ of ambient organic aerosol at a field site subject to biogenic and anthropogenic influences: relationship to degree of aerosol oxidation, Atmos. Chem. Phys., 10, 5047-5064, https://doi.org/10.5194/acp-10-5047-2010, 2010.

Cheng, Y., Zheng, G., Wei, C., Mu, Q., Zheng, B., Wang, Z., Gao, M., Zhang, Q., He, K., Carmichael, G., Pöschl, U., and Su, $\mathrm{H}$ : Reactive nitrogen chemistry in aerosol water as a source of sulfate during haze events in China, Sci. Adv., 2, e1601530, https://doi.org/10.1126/sciadv.1601530, 2016.

Chow, J. C., Watson, J. G., Lowenthal, D. H., and Magliano, K. L.: Loss of $\mathrm{PM}_{2.5}$ nitrate from filter samples in central California, J. Air Waste Manage., 55, 1158-1168, https://doi.org/10.1080/10473289.2005.10464704, 2005.

Clegg, S. L., Brimblecombe, P., and Wexler, A. S.: Thermodynamic model of the system $\mathrm{H}^{+}-\mathrm{NH}_{4}^{+}-\mathrm{SO}_{4}^{2-}-\mathrm{NO}_{3}^{-}-\mathrm{H}_{2} \mathrm{O}$ at tropospheric temperatures, J. Phys. Chem. A, 102, 2137-2154, https://doi.org/10.1021/jp973042r, 1998.

Dee, D. P., Uppala, S. M., Simmons, A. J., Berrisford, P., Poli, P., Kobayashi, S., Andrae, U., Balmaseda, M. A., Balsamo, G., Bauer, P., Bechtold, P., Beljaars, A. C. M., van de Berg, L., Bidlot, J., Bormann, N., Delsol, C., Dragani, R., Fuentes, M., Geer, A. J., Haimberger, L., Healy, S. B., Hersbach, H., Hólm, E. V., Isaksen, L., Kållberg, P., Köhler, M., Matricardi, M., McNally, A. P., Monge-Sanz, B. M., Morcrette, J.-J., Park, B.-K., Peubey, C., de Rosnay, P., Tavolato, C., Thépaut, J.-N., and Vitart, F.: The ERA-Interim reanalysis: configuration and performance of the data assimilation system, Q. J. Roy. Meteor. Soc., 137, 553-597, https://doi.org/10.1002/qj.828, 2011.
Fang, T., Guo, H., Zeng, L., Verma, V., Nenes, A., and Weber, R. J.: Highly Acidic Ambient Particles, Soluble Metals, and Oxidative Potential: A Link between Sulfate and Aerosol Toxicity, Environ. Sci. Technol., 51, 2611-2620, https://doi.org/10.1021/acs.est.6b06151, 2017.

Fountoukis, C. and Nenes, A.: ISORROPIA II: a computationally efficient thermodynamic equilibrium model for $\mathrm{K}^{+}$ $\mathrm{Ca}^{2+}-\mathrm{Mg}^{2+}-\mathrm{NH}_{4}^{+}-\mathrm{Na}^{+}-\mathrm{SO}_{4}^{2-}-\mathrm{NO}_{3}^{-}-\mathrm{Cl}^{-}-\mathrm{H}_{2} \mathrm{O}$ aerosols, Atmos. Chem. Phys., 7, 4639-4659, https://doi.org/10.5194/acp-74639-2007, 2007.

Guo, H., Liu, J., Froyd, K. D., Roberts, J. M., Veres, P. R., Hayes, P. L., Jimenez, J. L., Nenes, A., and Weber, R. J.: Fine particle $\mathrm{pH}$ and gas-particle phase partitioning of inorganic species in Pasadena, California, during the 2010 CalNex campaign, Atmos. Chem., Phys., 17, 5703-5719, https://doi.org/10.5194/acp17-5703-2017, 2017.

Guo, H., Otjes, R., Schlag, P., Kiendler-Scharr, A., Nenes, A., and Weber, R. J.: Effectiveness of ammonia reduction on control of fine particle nitrate, Atmos. Chem. Phys., 18, 12241-12256, https://doi.org/10.5194/acp-18-12241-2018, 2018.

Harris, E., Sinha, B., van Pinxteren, D., Tilgner, A., Fomba, K. W., Schneider, J., Roth, A., Gnauk, T., Fahlbusch, B., Mertes, S., Lee, T., Collett, J., Foley, S., Borrmann, S., Hoppe, P., and Herrmann, H.: Enhanced role of transition metal ion catalysis during in-cloud oxidation of $\mathrm{SO}_{2}$, Science, 340, 727-730, https://doi.org/10.1126/science.1230911, 2013.

Hennigan, C. J., Izumi, J., Sullivan, A. P., Weber, R. J., and Nenes, A.: A critical evaluation of proxy methods used to estimate the acidity of atmospheric particles, Atmos. Chem. Phys., 15, 27752790, https://doi.org/10.5194/acp-15-2775-2015, 2015.

Kim, B., Seo, J., Kim, J. Y., Lee, J. Y., and Kim, Y.: Transported vs. local contributions from secondary and biomass burning sources to $\mathrm{PM}_{2.5}$, Atmos. Environ., 144, 24-36, https://doi.org/10.1016/j.atmosenv.2016.08.072, 2016.

Kim, H. C., Kim, E., Bae, C., Cho, J. H., Kim, B.-U., and Kim, S.: Regional contributions to particulate matter concentration in the Seoul metropolitan area, South Korea: seasonal variation and sensitivity to meteorology and emissions inventory, Atmos. Chem. Phys., 17, 10315-10332, https://doi.org/10.5194/acp-1710315-2017, 2017.

Kim, Y., Seo, J., Kim, J. Y., Lee, J. Y., Kim, H., and Kim, B. M.: Characterization of $\mathrm{PM}_{2.5}$ and identification of transported secondary and biomass burning contribution in Seoul, Korea, Environ. Sci. Pollut. Res., 25, 4330-4343, https://doi.org/10.1007/s11356-017-0772-x, 2018.

Kim, Y. P. and Lee, G.: Trend of air quality in Seoul: policy and science, Aerosol Air Qual. Res., 18, 2141-2156, https://doi.org/10.4209/aaqr.2018.03.0081, 2018.

Kim, Y. P., Seinfeld, J. H., and Saxena, P.: Atmospheric gas-aerosol equilibrium I. Thermodynamic model, Aerosol Sci. Tech., 19, 157-181, https://doi.org/10.1080/02786829308959628, 1993.

KMA (Korea Meteorological Administration): Automated Synoptic Observing System (ASOS) data, available at: https://data.kma. go.kr/data/grnd/selectAsosRltmList.do?pgmNo=36, last access: 23 October 2019.

Korea Environment Corporation: Data from the NIER air quality monitoring sites, available at: https://www.airkorea.or.kr/web/ last_amb_hour_data?pMENU_NO=123, last access: 23 October 2019. 
Kusik, C. L. and Meissner H. P.: Electrolyte activity coefficients in inorganic processing, AIChE Symposium Series, 173, 14-20, 1978.

Lee, H.-J., Kim, S.-W., Brioude, J., Cooper, O. R., Frost, G. J., Kim, C.-H., Park, R. J., Trainer, M., and Woo, J.-H.: Transport of $\mathrm{NO}_{\mathrm{x}}$ in East Asia identified by satellite and in situ measurements and Lagrangian particle dispersion model simulations, J. Geophys. Res., 119, 2574-2596, https://doi.org/10.1002/2013JD021185, 2014.

Li, M., Zhang, Q., Kurokawa, J.-I., Woo, J.-H., He, K., Lu, Z., Ohara, T., Song, Y., Streets, D. G., Carmichael, G. R., Cheng, Y., Hong, C., Huo, H., Jiang, X., Kang, S., Liu, F., Su, H., and Zheng, B.: MIX: a mosaic Asian anthropogenic emission inventory under the international collaboration framework of the MICS-Asia and HTAP, Atmos. Chem. Phys., 17, 935-963, https://doi.org/10.5194/acp-17-935-2017, 2017.

Liu, Y., Wu, Z., Wang, Y., Xiao, Y., Gu, F., Zheng, J., Tan, T., Shang, D., Wu, Y., Zeng, L., Hu, M., Bateman, A. P., and Martin, S. T.: Submicrometer particles are in the liquid state during heavy haze episodes in the urban atmosphere of Beijing, China, Environ. Sci. Tech. Let., 4, 427-432, https://doi.org/10.1021/acs.estlett.7b00352, 2017.

Lim, Y. B., Seo, J., Kim, J. Y., Kim, Y. P., and Jin, H. C.: Local formation of sulfates contributes to the urban haze with regional transport origin, Environ. Res. Lett., https://doi.org/10.1088/1748-9326/ab83aa, in press, 2020.

Marais, E. A., Jacob, D. J., Jimenez, J. L., Campuzano-Jost, P., Day, D. A., Hu, W., Krechmer, J., Zhu, L., Kim, P. S., Miller, C. C., Fisher, J. A., Travis, K., Yu, K., Hanisco, T. F., Wolfe, G. M., Arkinson, H. L., Pye, H. O. T., Froyd, K. D., Liao, J., and McNeill, V. F.: Aqueous-phase mechanism for secondary organic aerosol formation from isoprene: application to the southeast United States and co-benefit of $\mathrm{SO}_{2}$ emission controls, Atmos. Chem. Phys., 16, 1603-1618, https://doi.org/10.5194/acp16-1603-2016, 2016.

McNeill, V. F.: Aqueous organic chemistry in the atmosphere: sources and chemical processing of organic aerosols, Environ. Sci. Technol., 49, 1237-1244, https://doi.org/10.1021/es5043707, 2015.

Nah, T., Guo, H., Sullivan, A. P., Chen, Y., Tanner, D. J., Nenes, A., Russell, A., Ng, N. L., Huey, L. G., and Weber, R. J.: Characterization of aerosol composition, aerosol acidity, and organic acid partitioning at an agriculturally intensive rural southeastern US site, Atmos. Chem. Phys., 18, 11471-11491, https://doi.org/10.5194/acp-18-11471-2018, 2018.

Nie, W., Wang, T., Gao, X., Pathak, R. K., Wang, X., Gao, R., Zhang, Q., Yang, L., and Wang, W.: Comparison among filterbased, impactor-based and continuous techniques for measuring atmospheric fine sulfate and nitrate, Atmos. Environ., 44, 43964403, https://doi.org/10.1016/j.atmosenv.2010.07.047, 2010.

NIER (National Institute of Environmental Research): National air pollutants emission 2015 (NIER-GP2017-210), NIER, Incheon, South Korea, available at: http://webbook.me.go.kr/DLi-File/ NIER/09/023/5668670.pdf (last access: 21 October 2019), 2018 (in Korean).

Nguyen, T. K. V., Capps, S. L., and Carlton, A. G.: Decreasing aerosol water is consistent with OC trends in the Southeast U.S., Environ. Sci. Technol., 49, 7843-7850, https://doi.org/10.1021/acs.est.5b00828, 2015.
Nguyen, T. K. V., Zhang, Q., Jimenez, J. L., Pike, M., and Carlton, A. G.: Liquid water: ubiquitous contributor to aerosol mass, Environ. Sci. Technol. Lett., 3, 257-263, https://doi.org/10.1021/acs.estlett.6b00167, 2016.

Phan, N.-T., Kim, K.-H., Shon, Z.-H., Jeon, E.-C., Jung, K., and Kim, N.-J.: Analysis of ammonia variation in the urban atmosphere, Atmos. Environ., 65, 177-185, https://doi.org/10.1016/j.atmosenv.2012.10.049, 2013.

Pope, C. A. and Dockery, D. W.: Health effects of fine particulate air pollution: lines that connect, J. Air Waste Manage., 56, 709-742, https://doi.org/10.1080/10473289.2006.10464485, 2006.

Seinfeld, J. H. and Pandis, S. N.: Atmospheric Chemistry and Physics: From Air Pollution to Climate Change, 3rd Edn., John Wiley \& Sons, Inc., Hoboken, New Jersey, 2016.

Seo, J., Kim, J. Y., Youn, D., Lee, J. Y., Kim, H., Lim, Y. B., Kim, Y., and Jin, H. C.: On the multiday haze in the Asian continental outflow: the important role of synoptic conditions combined with regional and local sources, Atmos. Chem. Phys., 17, 9311-9332, https://doi.org/10.5194/acp-17-9311-2017, 2017.

Seo, J., Park, D.-S. R., Kim, J. Y., Youn, D., Lim, Y. B., and Kim, Y.: Effects of meteorology and emissions on urban air quality: a quantitative statistical approach to long-term records (19992016) in Seoul, South Korea, Atmos. Chem. Phys., 18, 1612116137, https://doi.org/10.5194/acp-18-16121-2018, 2018.

Song, S., Gao, M., Xu, W., Shao, J., Shi, G., Wang, S., Wang, Y., Sun, Y., and McElroy, M. B.: Fine-particle $\mathrm{pH}$ for Beijing winter haze as inferred from different thermodynamic equilibrium models, Atmos. Chem. Phys., 18, 7423-7438, https://doi.org/10.5194/acp-18-7423-2018, 2018.

Stein, A. F., Draxler, R. R., Rolph, G. D., Stunder, B. J. B., Cohen, M. D., and Ngan, F.: NOAA's HYSPLIT atmospheric transport and dispersion modeling system, B. Am. Meteorol. Soc., 96, 2059-2077, https://doi.org/10.1175/BAMS-D-14$00110.1,2015$.

Stokes, R. H. and Robinson, R. A.: Interactions in aqueous nonelectrolyte solutions. I. Solute-solvent equilibria, J. Phys. Chem., 70, 2126-2131, https://doi.org/10.1021/j100879a010, 1966.

Sun, Y., Jiang, Q., Wang, Z., Fu, P., Li, J., Yang, T., and Yin, Y.: Investigation of the source and evolution processes of severe haze pollution in Beijing in January 2013, J. Geophys. Res.-Atmos. 119, 4380-4398, https://doi.org/10.1002/2014JD021641, 2014.

Takekawa, H., Minoura, H., and Yamazaki S.: Temperature dependence of secondary organic aerosol formation by photooxidation of hydrocarbons, Atmos. Environ., 37, 3413-3424, https://doi.org/10.1016/S1352-2310(03)00359-5, 2003.

Tie, X., Huang, R.-J., Cao, J., Zhang, Q., Cheng, Y., Su, H., Chang, D., Pöschl, U., Hoffmann, T., Dusek, U., Li, G., Worsnop, D. R., and O'Dowd, C. D.: Severe pollution in China amplified by atmospheric moisture, Sci. Rep., 7, 15760, https://doi.org/10.1038/s41598-017-15909-1, 2017.

Turpin, B. J. and Lim, H.-J.: Species contributions to $\mathrm{PM}_{2.5}$ mass concentrations: revisiting common assumptions for estimating organic mass, Aerosol Sci. Tech., 35, 602-610, https://doi.org/10.1080/02786820152051454, 2001.

van $\operatorname{der}$ A, R. J., Mijling, B., Ding, J., Koukouli, M. E., Liu, F., Li, Q., Mao, H., and Theys, N.: Cleaning up the air: Effectiveness of air quality policy for $\mathrm{SO}_{2}$ and $\mathrm{NO}_{x}$ emissions in China, Atmos. Chem. Phys., 17, 1775-1789, https://doi.org/10.5194/acp17-1775-2017, 2017. 
Vellingiri, K., Kim, K.-H., Jeon, J. Y., Brown, R. J. C., and Jung, M.-C.: Changes in $\mathrm{NO}_{x}$ and $\mathrm{O}_{3}$ concentrations over a decade at a central urban area of Seoul, Korea, Atmos. Environ., 112, 116125, https://doi.org/10.1016/j.atmosenv.2015.04.032, 2015.

Wang, G., Zhang, R., Gomez, M. E., Yang, L., Zamora, M. L., Hu, M., Lin, Y., Peng, J., Guo, S., Meng, J., Li, J., Cheng, C., Hu, T., Ren, Y., Wang, Y., Gao, J., Cao, J., An, Z., Zhou, W., Li, G., Wang, J., Tian, P., Marrero-Ortiz, W., Secrest, J., Du, Z., Zheng, J., Shang, D., Zeng, L., Shao, M., Wang, W., Huang, Y., Wang, Y., Zhu, Y., Li, Y., Hu, J., Pan, B., Cai, L., Cheng, Y., Ji, Y., Zhang, F., Rosenfeld, D., Liss, P. S., Duce, R. A., Kolb, C. E., and Molina, M. J.: Persistent sulfate formation from London fog to Chinese haze, P. Natl. Acad. Sci. USA, 113, 13630-13635, https://doi.org/10.1073/pnas.1616540113, 2016.

Wang, H., Lu, K., Chen, X., Zhu Q., Chen, Q., Guo, S., Jiang, M., Li, X., Shang, D., Tan, Z., Wu, Y., Wu, Z., Zou, Q., Zheng, Y., Zeng, L., Zhu, T., Hu, M., and Zhang, Y.: High $\mathrm{N}_{2} \mathrm{O}_{5}$ concentrations observed in urban Beijing: implications of a large nitrate formation pathway, Environ. Sci. Tech. Let., 4, 416-420, https://doi.org/10.1021/acs.estlett.7b00341, 2017.
Weber, R. J., Guo, H., Russell, A. G., and Nenes, A.: High aerosol acidity despite declining atmospheric sulfate concentrations over the past 15 years, Nat. Geosci., 9, 282-285, https://doi.org/10.1038/ngeo2665, 2016.

Wu, Z., Wang, Y., Tan, T., Zhu, Y., Li, M., Shang, D., Wang, H., Lu, K., Guo, S., Zeng, L., and Zhang, Y.: Aerosol liquid water driven by anthropogenic inorganic salts: Implying its key role in haze formation over the North China Plain, Environ. Sci. Tech. Let., 5, 160-166, https://doi.org/10.1021/acs.estlett.8b00021, 2018.

Zhang, R., Wang, G., Guo, S., Zamora, M. L., Ying, Q., Lin, Y., Wang, W., Hu, M., and Wang, Y: Formation of urban fine particulate matter, Chem. Rev., 115, 3803-3855, https://doi.org/10.1021/acs.chemrev.5b00067, 2015.

Zheng, G. J., Duan, F. K., Su, H., Ma, Y. L., Cheng, Y., Zheng, B., Zhang, Q., Huang, T., Kimoto, T., Chang, D., Pöschl, U., Cheng, Y. F., and He, K. B.: Exploring the severe winter haze in Beijing: the impact of synoptic weather, regional transport and heterogeneous reactions, Atmos. Chem. Phys., 15, 2969-2983, https://doi.org/10.5194/acp-15-2969-2015, 2015. 